\title{
La continuïtat «bioliterària» al País Valencià: de Carles Ros a Carles Salvador (o de Gregori Maians a Vicent Andrés Estellés, passant per Teodor Llorente)
}

\section{The «bioliterary» continuum in Valencian Country: from Carles Ros to Carles Salvador (or from Gregori Maians to Vicent Andrés Estellés, passing by Teodor Llorente)}

\author{
LLUÍs RODA \\ 1_roda@hotmail.com \\ Independent Scholar
}

\begin{abstract}
Resum: L'article fa evident un fil conductor que va dels novatores preil lustrats valencians de la fi del s. XVII fins a l'actualitat. També la connexió directa de València amb Londres i París al segle XIX -no sols amb Cadis, Madrid o Barcelona. Els poemes «En los dies del rei Fernando» d'Antoni Maria Peyrolon (1830) i «Lo somni» de Vicent Salvà (1831) són exponents valencians de cultura avançada. Teodor Llorente és també valorat com l'eix que connecta malgré lui l'esforç cultural dignificador valencià anterior a 1859 -amb l'Escola Pia de València com a focus primigeni de l'evolució romàntica- i l'esforç cultural dignificador valencià posterior a 1909. És a dir, entre la celebració dels Jocs Florals de València en honor a Ausiàs March l'any 1859 i l'emblemàtica coronació de Llorente com a poeta a València l'any 1909, que conclogué la Renaixença valenciana amb un èxit històricament suficient.
\end{abstract}

Paraules clau: Teodor Llorente, Renaixença, Vicent Salvà, Antoni Maria Peyrolon, Il lustració, Romanticisme, ss. xviii-xix

\begin{abstract}
This article presents evidence of a cultural continuum spanning from the pre-enlightened Valencian Novatores of the late 17th century to the present day. It also highlights the direct cultural connection of València with London and Paris during the first half of the 19th century -along with Cádiz, Madrid or Barcelona, which are more commonly acknowledged. In this context, the Valencian poems «En los dies del rei Fernando» by Antoni Maria Peyrolon (1830), and «Lo somni» by Vicent Salvà (1831) exhibit a high and up to date culture. This paper also evidences the Calasanzian Pious School of València as an early hub of the romantic shift. In 1859, València organized Jocs Florals -Floral Games- in celebration of Ausiàs March. Teodor Llorente, one of the winners, is regarded as the key link that connects the pre-1859 Valencian cultural dignifying efforts and the post-1909 ones. The popular event of Llorente's coronation as Poet in 1909 turned him an icon and concluded the Valencian Renaixença -Rebirth- with a historically sufficient success, as this work proves.
\end{abstract}

Keywords: Teodor Llorente, Renaixença, Vicent Salvà, Antoni Maria Peyrolon, Enlightment, Romanticism, Valencia, 18th c. - 19 th c.

DATA PRESENTACIÓ: 29/09/2015 ACCEPTACIÓ: 07/12/2015 · PUBLICACIÓ: 26/12/2015

SCRIPTA, Revista internacional de literatura i cultura medieval i moderna, núm. 6 / desembre 2015 / pp. 60 - 99 ISSN: 2340-4841 $\cdot$ doi:10.7203/SCRIPTA.6.7824 
Lluís Roda. La continuïtat «bioliterària» al País Valencià: de Carles Ros a Carles Salvador (o de Gregori Maians a Vicent Andrés Estellés, passant per Teodor Llorente)

\section{Teodor Llorente: un dels millors poetes de la Renaixença catalana}

La qualitat poètica de Teodor Llorente (1836-1911) ha estat decisiva per a l'èxit de la Renaixença literària valenciana. Clar i ras: sense Teodor Llorente no seríem ací. Ni enlloc. Ni Jacint Verdaguer ni Àngel Guimerà ni Frederic Mistral ni Constantí Llombart ni Vicent V. Querol tenien el pes suficient per a aconseguir-ho ací. Llorente no era sol, però sense ell no haguera estat possible la «continuïtat» per als valencians. ${ }^{1}$ A la indispensable qualitat literària, cal sumar el fet d'haver viscut «suficientment»: el temps necessari per dur a terme el relleu, per passar el testimoni en condicions aptes per a la particular cursa històrica dels valencians. Llorente era fill d'advocat i, dins la seua classe social, féu el forat necessari per a un tímid futur, remot però real, en el cas dels valencians. I no solament en relació al redescobriment i al record d'un passat nostrat important o a la constatació d'un present viu evanescent.

Llorente amalgamà el que calia per tal de possibilitar, gairebé del no-res, entre nobles precedents i conseqüents, un futur sense garanties. No encengué l'atxa. Però la va saber transmetre en condicions millors que l'havia rebuda. Féu llum a temps i n'encengué moltes, durant molt de temps. Establí una línia decisiva, bastí un model suficientment culte i popular alhora, que permetia ser perseverat, i ser eixamplat, més enllà del camp dels lletraferits, a la història, a la geografia, al periodisme i a la política. Establí relacions literàries normals amb Catalunya, fonamentals per a la nostra pervivència cultural: lingüística i literària. Unes relacions que van obrir una via natural perquè el tren del modernisme posterior, encapçalat per Joan Maragall, arribara també als poetes valencians més joves. Afortunadament, situà el llistó literari dignament alt, difícil de superar per coetanis o immediats. També pels més remots, molts dels quals en van seure plàcidament a l'ombra. Emulació i imitació sempre han estat actituds constants però diferents en la pràctica poètica general. La bona tradició és capaç d'estimular la pròpia continuïtat. La mimesi n'és la versió, per dir-ho així, defectuosa: urbi et orbi, omnipresent. Però un tronc sense arrels no pot créixer. I si creix, ha arrelat. Teodor Llorente fou un dels millors poetes de la Renaixença catalana.

La qualitat de Llorente se'ns fa evident en poemes com «Lo Rat Penat», «La reina de la festa», «La barraca», «A mon llibre», «Cartes de soldat», «Ma filla Irene», «Vora el barranc dels Algadins» o «Mal ensomni». També té aquesta qualitat Vicent V. Querol (1837-1889), el poeta de «Brindis», «A l'esperança» o «Patria, fides, amon», però els seus únics onze poemes escrits en català, entre 1859 i 1885, demostren un capficament menor, des del punt de vista lingüístic, per comparació a les cent quaranta-tres composicions de Teodor Llorente (Roca 2013a). La darrera edició en vida de Nou llibret de versos (1909) de Llorente reuní vuitanta-dos d'aquells poemes, i n’hi afegí vint-i-tres en relació a l'edició homònima anterior (datada 1902, publicada el 1903), la qual, al seu torn, ja era

\footnotetext{
1 Fuster (1962), en canvi, va afirmar: «cap poeta local no va tenir sobre el poble una suggestió tan difosa com la d'un Verdaguer o la d'un Guimerà». L'assagista de Sueca, a «Consideracions sobre la Renaixença» (1962: 221-234), parla de «fracàs», però, al nostre parer, resulta més adient parlar de «dificultats». La desafecció dels valencians envers la pròpia cultura potser ha estat menor del que s'ha emfasitzat, especialment, si atenem les circumstàncies que l'envoltaven, i que encara l'envolten.
}

SCRIPTA, Revista internacional de literatura i cultura medieval i moderna, núm. 6 / desembre 2015 / pp. 60 - 99 ISSN: 2340-4841 · doi:10.7203/SCRIPTA.6.7824 
Lluís Roda. La continuïtat «bioliterària» al País Valencià: de Carles Ros a Carles Salvador (o de Gregori Maians a Vicent Andrés Estellés, passant per Teodor Llorente)

una ampliació renovellada de la primera edició de Llibret de versos (1885). Dels trenta-set poemes del primer volum, en l'edició posterior de 1902, Llorente en conservà vint-i-nou, en suprimí vuit, i hi afegí trenta, fins a arribar a la quantitat de cinquanta-nou. De manera que la tasca poètica de Llorente fou ininterrompuda. De fet, entre el 1909 (l'any de l'Exposició i de l'espectacular coronació pública del poeta a València, com a homenatge i reconeixement alhora cultes i populars) i el 1911, hi ha datades dívuit composicions, de les quals cinc són del 1911 (l'any del seu traspàs). Entre aquestes, la significativa «Als poetes jóvens», publicada pòstumament, set dies després de la defunció de Llorente, a la revista Ilustració Catalana [sic], ${ }^{2}$ que dirigia Francesc Matheu (Roca 2013a: 679-682): « Oh jovenils poetes, que heu de ser nostra glòria!». Tot un testament de continuïtat.

\section{Les bases de la Renaixença al País Valencià: els predecessors de Teodor Llorente}

Els escriptors Pasqual Pérez (1804-1868), Josep Maria Bonilla, Nap-i-col (1808-1880), Josep Bernat i Baldoví (1809-1864), Tomàs Villarroya (1812-1856) i Vicent Boix, Lo Trobador del Túria (1813-1880) pertanyen a la generació precedent a Llorente que va crear les bases de la posterior Renaixença al País Valencià. Joan Arolas (1805-1849) ${ }^{3}$ i Antoni Aparisi i Guijarro (1815-1872) en són també uns referents propicis ineludibles.

A més dels susdits, altres intel lectuals i escriptors valencians del segle XIX, nascuts abans de Teodor Llorente (1836-1911), que convé no oblidar, són: ${ }^{4}$ Josep d’Orga i Pinyana (València 1800 - 1881), Venceslau Ayguals d’Izco (Vinaròs 1801 - Madrid 1873), Pere Labèrnia i Esteller (Traiguera 1802 - Barcelona 1860), Estanislau de Kostka Vayo (València, 1804 - 1864), Agustí Blat i Blat (València 1806 - 1874), Josep Joaquim Agulló i Ramon de Sentís, comte de Ripalda (1810-1876), Pere Salvà i Mallén (València 1811 - 1870), Rafael Vives i Azpiroz (València 1813 - 1886), Blai Bellver i Tomàs (Xàtiva 1818 - ?), Joan Antoni Almela (València 1819 - 1897), Lluís Gonçaga Llorente de las Casas (Elx 1822 - 1893), Cristòfol Pascual i Genís (València 1823 - 1881), Josep Pastor de la Roca (Dolores 1824 - Alacant 1875), Amàlia Fenollosa Peris (Castelló de la Plana 1825 - Barcelona 1869), Ramon Lladró i Mallí (València 1825 - 1896), Leandre Torromé (València 1825 - 1876), Francesc Tordera i Lledó (Alacant 1826 - 1889), Benet Altet i Ruate (València 1827 - 1893), Josep Ovara i Piquer (València 1827 - 1881), Joaquim Balader i Sanchis (València 1828 - 1893), Maria Orberà i Carrion (València 1829 - ?), Antoni Maria Ballester i Puchalt (València 1830 - Xixona 1891), Enric Escrig i González (València 1832 - Barcelona 1875), Francesc Bellido i Campos (València 1832 - 1889), Adolf Blanch i Cortada (Alacant 1832 - Barcelona 1887), Rafael Maria Liern i Celrach

\footnotetext{
2 Tinga en compte el lector que, en aquest article, el nom de les publicacions o de les citacions que en fem, els reproduïm sovint amb l'ortografia original.

3 De família de comerciants barcelonins, es traslladà a València als nou anys, estudià a les Escoles Pies, i ingressà a l'orde el 1819.

4 Ens limitem a donar-ne el nom i entre parèntesis el lloc i la data del naixement i de la mort, sense més detalls, ordenats per la data de naixença.
}

SCRIPTA, Revista internacional de literatura i cultura medieval i moderna, núm. 6 / desembre 2015 / pp. 60 - 99 ISSN: 2340-4841 · doi:10.7203/SCRIPTA.6.7824 
Lluís Roda. La continuïtat «bioliterària» al País Valencià: de Carles Ros a Carles Salvador (o de Gregori Maians a Vicent Andrés Estellés, passant per Teodor Llorente)

(València 1832 - Madrid 1897), Josep Maria Torres i Belda, lo sacristà de Tírig (Castelló de la Plana 1833 - València 1884), Jacint Labaila i González (València 1833 - 1895), Eduard Escalante i Mateu (Canyamelar 1834 - València 1895), Francesc Palanca i Roca (Alzira 1834 - València 1897), Vicent Sanchis i Roig (València 1835 - 1876). Quasi tots són precedents immediats de Llorente. No tots són poetes. Però gairebé tots van deixar alguna cosa escrita en la nostra llengua.

També cal esmentar Joaquim Garcia-Parreño i Lozano (Barcelona 1819 - 1880), que s’inicià com a actor professional al Teatre Principal de València l'any 1844, on estrenà un dels primers sainets valencians: Vicenteta la de Patraix (1845). Adoneu-vos que tots ells hauran mort quan es produirà el canvi de segle. Però sobreviuran a Teodor Llorente, Gaietà Salelles i Cardona (Gandia 1832 - 1916) i Josep Merelo (Castelló de la Plana 1833 - 1919), tots dos sainetistes.

Hi ha també uns altres autors, la data de naixement dels quals ignorem: Jaume Peyró i Dauder (València ? - Madrid 1874), Marià Suay (a.1849 - d. 1855), Joan Baptista Marqués i Aucher (...1855...), Frederic Blasco i Martínez (...1855...), Joan Baptista Llorens (a. 1855 - d. 1871). I hi ha també els sainetistes alcoians Vicent Zapaté i Vidal, Juli Puig, el gandienc Josep Roman, i el castellonenc Enric Pérez Ferrandis.

\section{Teodor Llorente l’any 1909: un símbol de pervivència}

Per això, podem afirmar que Llorente, directament o indirectament, els representa, els simbolitza, n'és l'hereu viu, conscientment o inconscientment. En aquest sentit, l'homenatge de 1909 a Teodor Llorente, cal veure'l també com l'homenatge a una pervivència reeixida. Si més no, ens correspon a nosaltres «entendre-ho» així. Llorente és la baula essencial d'un moment clau. Constantí Llombart (1848-1893), tot i ser dotze anys més jove que Teodor Llorente, va morir dívuit anys abans que el poeta de Llibret de versos.

Podem afirmar, per tant, que Llorente, en el segle xx, no solament representava el món cultural anterior a ell sinó també la tasca cívica transcendental duta a terme, sobretot per Constantí Llombart, des de Lo Rat-Penat. D'alguna manera, Llorente, l'any 1909, no representava solament la pròpia generació, sinó també la posterior. Especialment, quan considerem que gran part dels protagonistes nascuts entre Teodor Llorente (1836-1911) i Constantí Llombart (1848-1893) ja eren també morts en el moment de l'homenatge de 1909. Tanmateix, l'herència de tots ells anava a fer possible la nostra pervivència cultural i literària a través també del segle xx.

Aquella herència arribava viva a les nostres mans.

Tot seguit, oferim una relació incompleta, però il lustrativa, d'autors vinguts al món en els dotze anys que separen la data de naixença de tots dos i que ja eren morts l'any 1909: ${ }^{5}$ Rafael Ferrer i Bigné (València 1836 - 1892), Gaspar Thous i Orts (Benidorm 1836 - Isla de los Negros, Filipines

\footnotetext{
5 Sanchis Guarner (1982: 128) inclou Josep Peris Pasqual (1837-1897) dins la Generació de la Renaixença (1859-1878), però ignorem si mai va escriure res en català.
}

SCRIPTA, Revista internacional de literatura i cultura medieval i moderna, núm. 6 / desembre 2015 / pp. 60 - 99 ISSN: 2340-4841 · doi:10.7203/SCRIPTA.6.7824 
Lluís Roda. La continuïtat «bioliterària» al País Valencià: de Carles Ros a Carles Salvador (o de Gregori Maians a Vicent Andrés Estellés, passant per Teodor Llorente)

1891), Vicent V. Querol i Campos (València 1837 - Bétera 1889), Fèlix Pizcueta i Gallel (València 1837 - 1890), Miquel Amat i Maestre (Petrer 1837 - Alacant 1896), Salvador Estellés i Rams (València 1839 - 1861), Josep Manuel Blat i Soto (c. 1840 - c. 1863), ${ }^{6}$ Felip Benici Navarro i Reig

(València 1840 - Madrid 1901), Josep Garcia i Capilla (Almàssera 1840 - València 1902), Antoni Roig i Civera (Rafelbunyol 1844 - València 1898), Eduard Navarro i Gonzalvo (València 1846

- València 1902), Josep Fambuena i Ramírez (València 1847 - Madrid 1909), Josep Sanmartín i Aguirre (el Grau, València 1848 - Madrid 1901), Francesc Fayos i Antony (València 1848 - Barcelona 1904), Antoni Palanca i Hueso (València 1848 - 1905), Constantí Llombart [Carmel Navarro i Llombart] (València 1848 - 1893).

D’altres, no ho sabem: Vicent Guillot i Almonacid (València 1842 - ?), Vicent Tafalla i Campos (la Vila Joiosa 1842 - Alacant ?), Francesc de Paula Huertas i Rosell (València 1845 - ?), Josep Barreda i Pasqual (València 1845 - ?), Lluïsa Duran de Leon (Barcelona 1845 - d. 1883). Sabem que estan actius en les dates que oferim: Miquel Rosanes (...1864...), Josep Maria Cabrera (...1868...), Xavier Paulino Torres (a. 1898 - d. 1908).

Per tant, dels autors nascuts abans que Constantí Llombart, sols eren vius l'any 1909: Joaquim Martí i Gadea (Balones 1837 - Mislata 1920), Josep Arroyo i Almela (1839 - 1910), Manuela Agnés Rausell i Soriano (1839-1918), Josep Aguirre i Matiol (Vilanova del Grau, València 1842 - 1920), Josep Bodria i Roig (València 1842 - Alcoi 1912), Roc Chabàs i Llorens (Dénia 1844 - 1912), Josep Pérez Sànchez (Elx 1844 - 1918), Manuel Millàs i Casanoves (València 1845 - 1914), Joan Baptista Granell i Lledó (Sueca 1848 - 1919), Vicent Alarcon i Macià (Elx 1848 - 1922), Gaetà Huguet i Breva (Castelló de la Plana 1848 - 1926).

Teodor Llorente, doncs, era memòria viva. I tot un símbol per als valencians. El símbol de la nostra Renaixença (Fuster 1962: 232):

Llorente, malgrat tot, representava alguna cosa seriosa. [...] Llorente tenia llavors setanta-tres anys [...]. Però, en definitiva, ell era el màxim poeta valencià, el restaurador més distingit de l'idioma, una «institució».

\section{Teodor Llorente: pioner o continuador?}

Semblantment, els romàntics eren, al seu torn, els hereus «naturals» de les vicissituds del segle anterior: el XviII. El segle que havia vist nàixer Carles Ros i Hebrera (València 1703 - 1773) i Lluís Galiana i Cervera (Ontinyent 1740 - 1771), tots dos morts gairebé alhora, a pesar de la diferència

6 «Josep Manuel Blat i Soto, fill de l'impressor Agustí Blat i Blat, fou un precoç comediògraf i poeta, que ja als deu anys havia escrit dos romanços: "Font de la plaça de Calatrava" i "Nadal". La prematura mort, als vint-i-tres anys, privà sens dubte la Renaixença valenciana d'un ferm valedor.» (Simbor 1980: 129)

SCRIPTA, Revista internacional de literatura i cultura medieval i moderna, núm. 6 / desembre 2015 / pp. 60 - 99 ISSN: 2340-4841 · doi:10.7203/SCRIPTA.6.7824 
Lluís Roda. La continuïtat «bioliterària» al País Valencià: de Carles Ros a Carles Salvador (o de Gregori Maians a Vicent Andrés Estellés, passant per Teodor Llorente)

d'edat de trenta-set anys. D’una manera pareguda, Carles Ros i Lluís Galiana connectaven amb aquells intel lectuals nascuts en la darrera dècada del s. XVII: Vicent Ximeno i Sorlí (València 1691 - 1764), Josep Teixidor (el Grau, València 1694 - València 1775), Gregori Maians i Siscar (Oliva 1699 València 1781). Però Fuster sembla suggerir-nos un tall definitiu (1956: 27-28):

\begin{abstract}
La Renaixença valenciana serà un fillol de la Renaixença del Principat, i no, com Ros i Galiana podien fer preveure, una prolongació del moviment local setcentista innervat pels clàssics. «En el primer tercio del presente siglo -escriu Llorente a Rubió i Ors en 1887- no conozco ninguna persona de algún viso o regular ilustración que haya escrito en valenciano.»
\end{abstract}

Sens dubte, l'any 1887 restaven vives ja poques persones que pogueren contradir les afirmacions de Llorente. A més, Llorente mesura les seues paraules: «primer tercio del presente siglo». És cert que ell no havia nascut. Però va conéixer-ne alguns dels protagonistes. La notícia dels quatre poemes de Tomás Villarroya publicats entre el 1840 i el 1841, evidentment, no li era desconeguda. Villarroya (València 1812 - 1856) morí als quaranta-quatre anys, un any després que Llorente s'iniciara en l'escriptura poètica en català i dos anys abans de l'arribada de Marià Aguiló a València per l'abril de 1858. Cert és que en la determinació de Llorente, la influència de Marià Aguiló fou decisiva, com el poeta mateix li reconeix públicament en la dedicatòria-pròleg de la primera edició de Llibret de versos $(1885):^{7}$

\begin{abstract}
Havia arribat a ells [es refereix a ell mateix i a Querol com a «els dos escolars»] ja 1 ressò de la renaixensa llemosina; havien llegit ja los primers llibres de versos catalans; havien escoltat ja, en la mateixa València, a aquell precursor que 's nomenava Tomàs Villarroya, digne de figurar al costat del gran Aribau, y que, fa ja cuaranta anys, cantava versos tendríssims en la oblidada llengua dels seus avis / més dolsa que la mel; y tenien obert l'esment a aqueixa poesia, tan vella y tan nova tot alhora; mes els faltava ouir a un apòstol de aquell evangeli literari, un apòstol que inflamara son cor y els fera combregar en la santa comunitat dels trovadors nous.

Eixa missió d'apòstol, iquan bé la complíreu!
\end{abstract}

Però, òbviament, els joves Llorente i Querol no podien ignorar la presència de poemes en català en dos volums publicats l'any 1855 a València: Corona poética a San Vicente Ferrer en el cuarto siglo de su canonización i Álbum poético a la terminación del ferrocarril del Grao de Valencia a Játiva, dedicado al Señor Don José Campo, concesionario, Director-gerente y fundador de la Sociedad creada para tan laudable objeto, ja que també hi participaren, però en castellà. Encara. Els poemes de Villarroya no foren un fet aillat (Simbor 1980, 1988a). Però tal vegada Fuster (1956, 1980: 32) ho ignorava: «Probablement, quan Llorente s'incorpora a la Renaixença, el precedent de Villarroya [1812-1856] quedava ja una mica boirós, aillat i simbòlic, en la llunyania.» ${ }^{8}$

7 Citem de Roca (2013a: 729), que en reprodueix l'ortografia original: «Endressa. Al senyor Marian Aguiló, en la Biblioteca de la Universitat de Barcelona».

8 Els claudàtors sempre són nostres.

SCRIPTA, Revista internacional de literatura i cultura medieval i moderna, núm. 6 / desembre 2015 / pp. 60 - 99 ISSN: 2340-4841 · doi:10.7203/SCRIPTA.6.7824 
Tomàs Villarroya, convé aclarir-ho, era més un símptoma emergent que una raresa insòlita. I encara que abans es creia, com bé explica Simbor (1988a: 11), que els quatre poemes havien estat publicats al Liceo Valenciano entre el 1841 i el 1842 (que foren els dos anys que durà aquest periòdic, primer setmanal, i després mensual), dos d'aquells poemes havien estat ja publicats l'any anterior al Diario Mercantil de Valencia, ${ }^{9}$ el diari que Pasqual Pérez i Rodríguez (1804-1868) fundà el 1833, amb Joan Arolas (1805-1849) i Pere Sabater (amb qui Tomàs Villarroya compartia despatx d'advocat), i que Pérez va dirigir fins el $1844 .^{10}$

El Diario Mercantil de Valencia ja havia editat un llarg annex el 6 d'octubre de 1838 on s'adheria a les celebracions, justificant-les, que anaven a tenir lloc a València per l'efemèride del sis-cents aniversari de la conquesta de la ciutat per part de Jaume I, alhora que recordava les que havien tingut lloc un segle abans: «y anudar, digámoslo asi, con un eslabon viviente la solemnidad de hace cien años con la solemnidad presente». I demostrava una nítida consciència històrica quan hi afirmava:

\begin{abstract}
[...] mas para los que saben pensar y leer, para los que analizan el espíritu del hombre y la historia del mundo, para los que no ignoran cuán identificadas se hallan éstas al parecer pequeñeces y futilidades con los grandes intereses de los pueblos, siendo al propio tiempo su gloria, monumento, carácter y estímulo; no serán inútiles, no serán despreciables semejantes recuerdos. [...] comprendemos el deber y lo abrazamos [...] sirvan de monumento y material á los que vivan el año 1938. Semejante tarea pide otras circunstancias y aptitud que la nuestra, y no dudamos será dignamente desempeñada por el historiador elegido á perpetuar la memoria de la presente solemnidad secular.
\end{abstract}

L’annex anava encapçalat per una composició lírica que acabava així:
Valencianos, nuestra gloria
De tiempo antiguo mirad,
El esfuerzo contemplad
De un Rey valiente y divino.
Que él nos enseñó el camino
De la dulce libertad.

També constatem una important voluntat programàtica, orientada al futur, en la notícia de bones intencions que podem llegir al número d'abril de 1842 del Liceo Valenciano en una nota a peu de

\footnotetext{
9 El 23 de gener i el 8 d'agost de 1840.

10 Arolas era amic tant de Pasqual Pérez com de Vicent Boix (1813-1880). Pere Sabater i Vicent Boix també es coneixien: «A l'esquerra s'anaren formant nuclis republicans, sovint en contacte amb les societats secretes (especialment, els carbonaris, amb el club La Barraca, de València). L'intent moderat (1841) de Diego de León provocà la creació d'una Junta de Vigilància i Seguretat, presidida per Manuel Bertran de Lis (amb elements moderats, com Vicent Boix i d'altres més radicals com Tomàs Cervera i Francesc Usera). Els anys 1842 i 1843 hi hagué intents de secundar les revoltes del Principat; el darrer (amb creació d’una Junta de salvació de què formaven part Pere Sabater i V. Boix) influí en la caiguda del regent i la proclamació de la majoritat d’Isabel II.» (GEC «El País Valencià»)
}

SCRIPTA, Revista internacional de literatura i cultura medieval i moderna, núm. 6 / desembre 2015 / pp. 60 - 99 ISSN: 2340-4841 · doi:10.7203/SCRIPTA.6.7824 
Lluís Roda. La continuïtat «bioliterària» al País Valencià: de Carles Ros a Carles Salvador (o de Gregori Maians a Vicent Andrés Estellés, passant per Teodor Llorente)

pàgina de l'article «Brevisima Descripcion de la Biblioteca de la Universidad de Valencia», signat pel comte de Ripalda [Josep Joaquim Agulló i Ramon de Sentís (1810-1876)], autor que quatre anys més tard, el 29 de novembre de 1846, publicarà a El Fénix «Poesia llemosina al casament real». ${ }^{11} \mathrm{La}$ notícia diu:

\begin{abstract}
Otra rica coleccion de poetas lemosines (1) [(1) Algunos señores socios del Liceo de esta ciudad, conocidos y estimados por mil justos títulos, se ocupan en hacer una coleccion de los mejores poetas valencianos, que se publicará á la mayor brevedad.], entre ella cuatro distintas ediciones del Auxias March [sic], y la mayor parte de las obras que se imprimieron en Valencia en el siglo xv, principiando por las Tròves á la Sacratíssima Vèrge Maria en 1474, que fue el primer libro que se imprimió en España. (p. 176)
\end{abstract}

El Liceo Valenciano fou una institució cultural creada a València el 1836 per Fermí Gonçal Moron, Antoni Rodríguez de Cepeda, Joan Sunyé, Ignasi Vidal, Manuel Benedito i Pere Sabater. I entre 1841 i 1842 va editar el periòdic homònim on Tomàs Villarroya va publicar quatre poemes en català. D'aquest Liceu de València, en van formar part Querol, Llorente, Pasqual Pérez, Altet i Ruate, Miquel Amat, Pérez i Pujol, Ferrer i Matutano, Ciril Amorós, etc. El Liceo va omplir molts anys de la història cultural de València (1836-1863). L'any 1962, el poeta Francesc Almela i Vives (1903-1967) va escriure El Liceo Valenciano: sus figuras y sus actividades. ${ }^{12}$ Fou, precisament, aquesta entitat la que convocà l'any 1859 uns Jocs Florals a València (Tomàs 2012: 34-45), considerats l'inici d'una nova etapa de la Renaixença valenciana. Però no oblidem que València, l'any 1855, ja havia volgut commemorar, literàriament també, de forma molt emblemàtica, el cinc-cents aniversari de la canonització de sant Vicent Ferrer, amb l'edició d'un volum poètic amb la contribució de la pràctica totalitat dels poetes valencians del moment.

\title{
5. Carles Ros i Lluís Galiana no eren sols al s. XvIII
}

És el moment de recordar que Carles Ros (1703-1773) i Lluís Galiana (1740-1771) no van estar del tot sols. I que en vida de Gregori Maians i Siscar (Oliva 1699 - València 1781) va nàixer una respectable collita d'intel lectuals i d'escriptors al País Valencià, entre altres: Vicent Josep Marc i Borràs (Castelló de la Plana, ? - València 1796), Pasqual Esclapers de Guilló (Elx 1700 - València 1755), Pasqual Berguedà (València 1702 - 1779), Josep Esplugues i Revert (Agullent 1705 Montaverner 1787), Agustí Sales i Alcalà (Valljunquera, Matarranya 1707 - València 1774), ${ }^{13}$ Vicent

11 El setmanari El Fénix fou publicat a València entre 1844 i 1849. Entre els col laboradors hi ha Lluís Miquel i Roca, Joan Antoni Almela, Francesc i Joan Arolas, Josep M. Zacarés, Vicent Boix i Ricart, Ramon Ferrer i Matutano, Pelegrí Garcia i Cadena, etc. Fou fundat per Rafael de Carvajal. Veg. Almela (1957).

12 Abans, F. Almela havia ja havia publicat El editor don Mariano de Cabrerizo (1949) i també El Fénix: Valencia 1844-1849 (1957).

13 Fou cronista de la ciutat i Regne de València des del 1738 fins que va morir el 1774. Fou amic de Gregori Maians i

SCRIPTA, Revista internacional de literatura i cultura medieval i moderna, núm. 6 / desembre 2015 / pp. 60 - 99 ISSN: 2340-4841 · doi:10.7203/SCRIPTA.6.7824 
Lluís Roda. La continuïtat «bioliterària» al País Valencià: de Carles Ros a Carles Salvador (o de Gregori Maians a Vicent Andrés Estellés, passant per Teodor Llorente)

Tomàs Tarifa (1708 - València 1773), Francesc Vicent Pérez i Bàier (València 1711 - 1794), Jordi Joan i Santacília (Novelda 1713 - Madrid 1773), Tomàs Serrano i Peres (Castalla 1715 - Bolonya, Itàlia 1784), Manuel Fuster i Membrado (la Todolella, els Ports 1717 - València 1793), Joan Antoni Maians i Siscar (Oliva 1718 - València 1801), Bartomeu Tormo (Albaida 1718 - Caudete de las Fuentes, Plana d’Utiel 1773), Joan Baptista Hermán i Aranda (Serón, Almería 1727 - Granada? 1794), Vicent Antoni Noguera i Ramon (València 1728 - 1797), Antoni Eiximeno i Pujades (València 1729 - Roma 1808), Vicent Emperador i Pichó (València 1730 - Ferrara 1797), Marc Antoni Orellana (València 1731 - 1813), Joan Collado (València 1731 - 1767), Josep Villarroya (València 1732 - 1804), Lluís Ballester i Pallardó (València 1733 - 1817), Josep Marià Ortís (València 1735 - 1799), Manuel Martín i Picó (Castelló de la Plana 1736 - València 1810), Manuel Lassala i Sangerman (València 1738 - 1806), Francesc Cerdà i Rico (Castalla 1739 - Madrid 1800), Bernat Garcia (València 1740 - Venècia 1800), Joan Andrés i Morell (Planes de la Baronia, Comtat 1740 - Roma 1817), Joan Baptista Colomers (València 1740 - Bolonya 1807), Pere Cerís i Gelabert (València 1743 - Ferrara 1795), Joan Francesc de Masdeu i de Montero (Palerm, Sicília 1744 - València 1817), Joan Baptista Muñoz (Museros 1745 - València 1799), Antoni Josep Cavanilles (València 1745 - Madrid 1804), Francesc Xavier Borrull i Vilanova (València 1745 - 1837), Pere Montengon i Paret (Alacant 1745 - Nàpols 1824), Francesc Bahamonde i Sesé (València 1750 - 1805), Marià Llorente (València 1752 - Bolonya 1816), Joan Baptista Escorihuela (València 1753 - 1817), Joan Sempere i Guarinos (Elda 1754 - 1830), Lleó d’Arroyal (Gandia 1755 - 1813), Joaquim Llorenç Villanueva i Astengo (Xàtiva 1757 - Dublín 1837), Manuel Joaquim Sanelo i Lagardela (Xàtiva 1760 - 1829), Just Pastor Fuster i Taronger (València 1761 - 1835), Macià Blanquer (Callosa d'en Sarrià 1761 - 1828), Carles Leon (1762 - 1836), Vicent Martínez i Colomer (Beniflà, Safor 1763 - València 1820), Jaume Villanueva i Astengo (Xàtiva 1765 - Londres 1824), Pere Picó i Rius (València 1767 - Xàtiva 1819), Pasqual Martínez i Garcia (València 1772 - Carlet 1842), Tomàs Font i Piris (Cullera 1772 - 1831/1853?), Onofre Soler i Rubio (c. 1779 - 1834).

\section{De la Il lustració al Romanticisme}

D'aquesta connexió, serveix de testimoni el comentari que el Liceo Valenciano publica, en la presentació d'un poema de Tomàs Villarroya (1812-1856), al número de setembre de 1841 (pp. 215-216), en recordar un precedent, de cognom homònim, Josep Villarroya (1732 - 1804):

[...] y nosotros solo podemos esplicarle recurriendo al deseo natural en todos los hombres de imitar aquello por que se hicieron célebres nuestros mayores, y mas particularmente los que llevaron nuestros nombre. [...] No hay ningun valenciano que no sepa que á fines del siglo pasado existia en esta ciudad un literato célebre llamado José Villarroya, que hizo importantísimos servicios á la literatura provincial. Dedicado al exámen de nuestra antigua

prologà el Diccionario valenciano-castellano de Carles Ros (1764), entre altres.

SCRIPTA, Revista internacional de literatura i cultura medieval i moderna, núm. 6 / desembre 2015 / pp. 60 - 99 ISSN: 2340-4841 · doi:10.7203/SCRIPTA.6.7824 
Lluís Roda. La continuïtat «bioliterària» al País Valencià: de Carles Ros a Carles Salvador (o de Gregori Maians a Vicent Andrés Estellés, passant per Teodor Llorente)

\begin{abstract}
legislacion, publicó varias obras del mayor interes sobre nuestros fueros, y no contento con hacer justicia á nuestros legisladores, quiso hacerla tambien á nuestros compatriotas publicando á su vez una disertacion sobre el origen del arte tipográfico [sic], en la que trató de probar y probó que Valencia fue la primera provincia de España en que se conoció la imprenta.[...] han hecho que en nuestros dias apareciese otro Villarroya destinado como el primero á dar gloria y prez á la literatura lemosina. No hay sino leer la composicion que á seguida insertamos [...] si D. José Villarroya supo probar que la obra del Verger de la Verge Maria fue una de las primeras impresiones que se vieron en España, nuestro contemporáneo D. Tomás ha sabido tambien probar que la lengua valenciana por su dulzura, laconismo y espresion era digna de ser otra de las primeras que hiciera trabajar á la imprenta. Facil nos seria citar otras composiciones del mismo autor en corroboracion de nuestro aserto (1) [(1) Y sino véase entre otras la que insertamos en el núm. 3, dirigida á la muerte del jóven pintor D. Antonio Cabana, en donde se hallan aquella energía y espresion y demas cualidades con que el autor sabe adornar todas sus composiciones, imprimiendo en ellas toda la belleza y propiedad de que es capaz la lengua valenciana. Sentimos mucho que algunos de nuestros mejores literatos no esten en el caso de apreciar el mérito de estas producciones, pues estamos seguros que entonces convendrán con nosotros en la distincion que de ellas hacemos.]; reservándonos la insercion de otras no menos lindas para los números sucesivos. Entre tanto rogámosle á nuestro amigo que continúe siendo el defensor de la lengua lemosina y del gay saber, seguro de que sus compatriotas le guardan una de las páginas mas brillantes en la biblioteca valenciana.
\end{abstract}

Però seran principalment els autors nascuts a partir de 1781, l'any de la mort de Gregori Maians i Ciscar (el qual sobrevisqué a Ros i a Galiana, si fa no fa, una dècada), els que, a partir de l'herència anterior, protagonitzaran els canvis del primer terç del segle XIX. ${ }^{14}$ Ells també permetran la continuïtat cultural. Són els primers protagonistes d’uns temps convulsos i crucials: Esteve Chaix (Xàtiva, ? - Xàtiva 1813), Manuel Civera, lo Fideuer o lo Semolero (València s. XVIII ? - València 1822), Nicolau Peres (Xàtiva, ? - 1828), Vicent Clèrigues, el Bolònio (València ? - Castelló de la Plana 1835), Melcior Vilaplana, el tio Melcior (Benimarfull 1782 - 1835), Mariano de Cabrerizo y Bascuas (La Vilueña, Aragó 1785 - València 1868), Vicent Salvà i Pérez (València 1786 - París 1849), Francesc Brotons (València 1786 - 1865), Lluís Navarro (Alboraia 1788 - València 1846), Vicent Manuel Branchat i Alfonso (a. 1791 - d. 1819), Josep Escrig i Martínez (Llíria 1791 - 1867), Lluís Lamarca i Morata (Torrent 1793 - València 1850), Antoni Maria Peyrolon (a. 1813 - d. 1840), ${ }^{15}$ Vicent Anglés i Lliberio (...1840...), Antoni Garcés de Marcilla, baró d’Andilla (1797-1883).

14 Vicent Salvador (2001: 107) refereix «la pobresa cultural del XVIII valencià, il lustrats a part». Però, òbviament, és un error prescindir dels il lustrats en parlar del segle XvIII arreu d'Europa ja que són el sector cultural més avançat. I el fet que s'expressen en català, castellà o llatí, no ens ho hauria d'impedir observar. La societat valenciana no va quedar endarrerida. Sí, subjugada a uns nous poders dins un tauler de joc diferent i canviant. Com sabem, el llatí no solament era la llengua dels teòlegs, sinó també d'una gran part de la filosofia i de la ciència. I que amb la formació actual ja no l'entenguem no vol dir que no tinga valor. Precisament, sembla apuntar en aquest sentit l'afirmació de Fuster que Salvador mateix cita (108): «No entendrem mai la "cultura catalana" si la reduïm al català». Una cultura que també sabem que si prescindira del català que la compacta es dissoldria fins a extingir-se ràpidament. Salvador, abans, també cita Fuster (104): «Encara no sabem massa coses sobre els primers romàntics de València: ni tan sols quins van ser els conductes, via París, via Madrid, via Barcelona, per on van arribar els estímuls modernitzadors. Però per ací trobarem el desllorigador».

15 Les dues dates són resultat d’una indagació que presentarem en un altre article.

SCRIPTA, Revista internacional de literatura i cultura medieval i moderna, núm. 6 / desembre 2015 / pp. 60 - 99 ISSN: 2340-4841 · doi:10.7203/SCRIPTA.6.7824 
Lluís Roda. La continuïtat «bioliterària» al País Valencià: de Carles Ros a Carles Salvador (o de Gregori Maians a Vicent Andrés Estellés, passant per Teodor Llorente)

Potser encara no s'ha posat suficient èmfasi a subratllar la importància de les Escoles Pies de València. Els escolapis van arribar a València l'any 1737, de la mà del comte de Carlet, quasi noranta anys després de la mort del seu fundador, Josep de Calassanç (Peralta de la Sal, la Llitera 1557 - Roma 1648), el qual havia estudiat Filosofia a la Universitat de Lleida i Teologia a la Universitat de València i Alcalá de Henares. L'any 1592, després d'un periple per parròquies del bisbat d'Urgell, marxà a Roma i cinc anys més tard hi aconseguí fundar sense cap ajut la primera escola gratuita per a pobres a Europa. Es tractava de formar tant l'intel lecte com l'esperit, i estava oberta a cristians i jueus, als quals s'ensenyava sense intentar-ne la conversió. A més de l'ideal calassancià d'educar tots els nens, especialment els pobres, les escoles mostraren suport a les teories heliocèntriques de Galileo Galilei (1564 - 1642), a les ciències i a la matemàtica. A mitjan segle XVIII, els escolapis d'Aragó i València van desterrar els llibres eclesiàstics en les classes de traducció llatina substituint-los pels clàssics romans, que eren pagans. A València, es fundà el col legi de Sant Joaquim, al carrer de Carnissers. Vicent Salvà (València 1786 - París 1849) en fou alumne. El Seminari Andresià començà a funcionar l'any 1763. Vegeu les contribucions de Telesforo M. Hernández, Vicente León Navarro i Nicolás Bas Martín per avançar en la comprensió de la complexitat del pas de la Il lustració al Romanticisme a casa nostra. ${ }^{16}$

Hi trobem un quadrilàter ple de ramificacions que emmarca un procés tan extraordinari com aquest: el format pels germans Maians i Siscar: Gregori (1699-1781) i Joan Antoni (1718-1801); per la saga dels llibreters Mallén: des del primer, Joan Antoni, d'origen francés i de qui ja tenim notícies l'any 1746 per la correspondència que manté amb el seu client Maians (seguit en el negoci pel seu fill Dídac, qui en morir l'any 1799 fou succeït també, al seu torn, pel seu fill Pere Joan); per la saga dels Salvà: Vicent (València 1786 - París 1849), qui va casar amb Josefa Mallén el 30 d'agost de 1809, germana de Pere Joan, i es vinculà a l'activitat familiar, no solament com a llibreter, sinó també com a editor i bibliòfil, tascà que comptà amb la col laboració i la continuïtat del seu fill Pere Salvà i Mallén (València 1811 - 1870), ${ }^{17}$ a l'activitat a València dels quals també es va afegir a partir de 1809 la llibreria de Marià de Cabrerizo (1785-1868); ${ }^{18}$ finalment, hi ha els germans Villanueva i Astengo: Joaquim Llorenç (Xàtiva 1757 - Dublín 1837), i Jaume (Xàtiva 1765 - Londres 1824). ${ }^{19}$ El cercle, doncs, de les Escoles Pies tenia on arrelar i créixer. Des d'on multiplicar-se.

16 Hernández, T. M. (1997) «Enseñanza de latinidad y humanidades en la renovación pedagógica del seminario andresiano de nobles (1763-1785)». I en col laboració amb León Navarro, V. (2002) «El Real Seminario de Nobles Educandos de Valencia (1767-1784). ¿Un símbolo del reformismo educativo?». León Navarro, V. (1998) «Juan Bautista Hermán: discípulo de Gregorio Mayans. Los entresijos de la curia valenciana. Una persecución en dos actos». I Bas Martín, N. (2002) Las bibliografías de la Ilustración valenciana; (2006) «Apertura política e intelectual de los impresores valencianos de la Ilustración al Liberalismo»; (2013) «Un soplo de aire fresco: libros franceses en los Catálogos del siglo XVIII de la librería Mallén de Valencia». També Villacañas, J. L. (2003) «Las raíces ilustradas del Liberalismo».

17 Veg. Reig Salvá, C. (1972) Vicente Salvá, un valenciano de prestigio internacional. I també Seguí Francès, R. (1999) «Vicent i Pere Salvà o la memòria de la Biblioteca del XIX»; (2005) «La recuperació del patrimoni bibliogràfic valencià al segle XVIII. La Biblioteca Valentina de Josep Rodríguez i Escritores del Reyno de Valencia de Vicent Ximeno». El catàleg de Pere Salvà fou publicat dos anys després de la seua mort (1872) Catálogo de la Biblioteca de Salvá escrito por Pedro Salva y Mallen. 18 Veg. F. Almela (1949) El editor don Mariano de Cabrerizo. També G. Sansano (1996).

19 Veg. Ramírez G. (1996, ed.) Vida literaria de Don Joaquín Lorenzo Villanueva; (2003) «La Santa Sede ante la revolución liberal española: diplomacia y política en el Trienio Constitucional»; (2009, ed.) Valencianos en Cádiæ: Joaquín Lorenz̧o Villanueva y el grupo valenciano en las Cortes de Cádiz.

SCRIPTA, Revista internacional de literatura i cultura medieval i moderna, núm. 6 / desembre 2015 / pp. 60 - 99 ISSN: 2340-4841 · doi:10.7203/SCRIPTA.6.7824 
Lluís Roda. La continuïtat «bioliterària» al País Valencià: de Carles Ros a Carles Salvador (o de Gregori Maians a Vicent Andrés Estellés, passant per Teodor Llorente)

No a tot arreu era possible aconseguir les novetats europees, especialment, els llibres prohibits que circulaven per Europa. Però els llibreters Salvà i Mallén eren al peu d'aquest canó. Convé recordar que la població instruïda podia llegir en llatí, en francés o en anglés. Sens dubte, les traduccions al castellà es van fer servir per tal d'acréixer la popularitat de certes idees i dels gustos novells. Però als il lustrats o liberals capdavanters, no els calia. L'accés era per força directe i d'amagat de la inquisició. ${ }^{20}$ D’una forma important, molt probablement, via València, via Mallén, via Salvà. També via tertúlies, com les que tingueren lloc a la llibreria de Cabrerizo.

\section{La traducció de la Bíblia a la nostra llengua}

No volem obviar un assumpte, la transcendència del qual no estem encara en condicions de valorar: l'afer, suscitat a Londres, de la traducció de la Bíblia al català, sota els auspicis de The British and Foreign Bible Society, on intervingueren, d'una forma oposada, dos intel lectuals que s'havien conegut a la universitat d'Alcalá de Henares l'any 1807, on Vicent Salvà (València 1786 - París 1849) arribà com a professor de llengua grega i on Antoni Puig i Blanch (Mataró 1795 - Londres 1840), que havia estudiat als escolapis de Mataró, acabava de ser nomenat professor d'hebreu. La persecució contra els liberals a partir de 1814 els portà a exilis diferents: Puigblanch, nom de ploma d'Antoni, marxà a Londres, mentre que Salvà anà a Itàlia i a França. Després, tots dos van ser elegits diputats a corts a Madrid durant el trienni liberal. Tots dos visqueren a partir de 1824 l'exili a Londres. L'any 1828 Vicent Salvà va proposar com a traductor de la Bíblia al català, Joaquim Llorenç Villanueva i Astengo (Xàtiva 1757 - Dublín 1837), qui l’any 1791, a València, havia publicat De la lección de la Sagrada Escritura en lenguas vulgares. Antoni Puig i Blanch, per contra, defensà Josep Melcior Prat i Sala (els Prats de Rei 1781 - Sant Sebastià 1855), qui finalment va ser el traductor escollit. Tant Villanueva com Prat, Salvà com Puig i Blanch, eren exiliats a Londres. Ramon Bussanya, també a l'exili a Anglaterra, supervisà la qualitat de la llengua de la traducció de Prat. El volum va ser publicat, primerament, a Londres l'any 1832: Lo Nou Testament de Nostre Senyor Jesu-Christ. Vicent Salvà va escriure el poema «Lo somni» l'any 1831, durant el seu exili a París. L'any 1830, un any abans, al Diario de Valencia, Antoni Maria Peyrolon havia publicat «En los dies del nostre rei Fernando». Tots dos poemes eren ben valuosos. I capdavanters del romanticisme en català.

\section{Chateaubriand per ací}

L'any 1803 ja es publica a València una traducció al castellà d'Atala (1801) de Chateaubriand, la primera feta a la península, signada per J. P. R. (Pascual Genaro Ródenas). També a València, l’any

20 Veg. Astorgano, A. (2005) «El inquisidor Rodríguez Laso y el ocaso de la Inquisición valenciana (1814-1820)». 
Lluís Roda. La continuïtat «bioliterària» al País Valencià: de Carles Ros a Carles Salvador (o de Gregori Maians a Vicent Andrés Estellés, passant per Teodor Llorente)

1813, es publica Vida del joven René (1802), reeditada el 1827. El traductor hi escrigué un pròleg, però no donà el seu nom, tampoc no féu esment de la traducció de Torcuato Torío de la Riva, publicada a Madrid l'any 1806 dins Genio del cristianismo, obra de Chateaubriand de 1802, que incloïa totes dues. La traducció de 1813 és del franciscà valencià Vicent Martínez i Colomer (Beniflà, la Safor 1763 - València 1820), cronista provincial de l'orde, que ja havia escrit El filosofo en su quinta (1808) i Sucesos de Valencia desde el día 23 de mayo hasta el 28 de junio de 1808 (1810). Veg. Giné (1999) i Lafarga (2013). Joan Arolas (1805-1849) va traduir un volum de poemes de Chateaubriand l'any 1846. En relació a la cinquena edició de 1835 d'Atala (J. Ferrer de Orga, València), Pere Salvà diu (1872): «Esta traduccion fué corregida por mi padre». Rubió i Ors (1818-1899) reconegué l'impacte que li provocà Génie du christianisme de Chateaubriand. També la lectura de Joan Arolas.

\section{Les Escoles Pies de València i els precedents als Jocs Florals de 1859}

A València, hi coincidiren, formant part de l'orde dels escolapis, Jaume Vicente (? - 1833), ${ }^{21}$ Joan Arolas (1805-1849), Pasqual Pérez i Rodríguez (1804-1868)22 i Vicent Boix (1813-1880), entre ells establiren lligams d'amistat duradors.

Pasqual Pérez estudià becat al Seminari Andresià de les Escoles Pies i després fou religiós escolapi fins l'any 1835, quan s'exclaustrà. Sembla que Pérez tenia un lligam familiar amb Vicent Boix (Faubell 1983: «Vicente Boix Ricarte»), que també s'exclaustrà un parell d'anys després, l'any 1837. A més de Pasqual Pérez, estigueren també internats al Seminari Andresià, Bernat i Baldoví (18091864), Aparisi i Guijarro (1815-1872), Jacint Labaila (1833-1890) i Fèlix Pizcueta (1837-1890). ${ }^{23}$

Joan Arolas i Vicent Boix també havien estat alumnes del col legi abans. La família de Joan Arolas, nascut a Barcelona, es va establir a València l'any 1814. Condeixebles de Vicent Boix hi foren Aparisi y Guijarro (1815-1872), Pere Sabater i Tomàs Villarroya i Sanz (1812-1856). Segons Faubell $(1990):^{24}$

21 «Nota 47: Fallecido en 1833; cf R III pp. 471-473», Enric Ferrer i Solivares dins «Síntesis de historia de la orden de las escuelas pías. III Las escuelas pías en el siglo xix: de la desintegracion (1804) a la reunificacion (1904). 1 Descripción de la Orden (hasta 1904): Introducción.» (FerrerSintesis): http://wiki.scolopi.net/w/index. php?title=FerrerSintesis/3SigloXIX/1Descripci\%C3\%B3n

22 Amb J. Arolas i Pere Sabater, P. Pérez fundà El diario mercantil el 1833. Tant Pasqual Pérez com Bernat i Baldoví col laboraren amb Josep M. Bonilla a El Mole (1837): «Periòdic satíric d'idees liberals en català, aparegut a València l'1 de febrer de 1837, fundat i redactat per Josep Maria Bonilla. Tingué un gran èxit de públic (3.000 subscriptors el 1840) i pot ésser considerat com el capdavanter de les idees liberals al País Valencià i de la Renaixença, tant per l'ardida defensa de la llengua com per les seves contribucions al recobrament de la consciència valenciana. A conseqüència de processos i suspensions múltiples tingué diverses etapes: 1837, 1840-1841, 1854, 1855, 1863-1864, El Mole Antic 18641865, 1870. Per motius de censura hagué de canviar sovint de nom. [...] Esporàdicament hi col laboraren, quasi sempre amb pseudònim, Pasqual Pérez i Rodríguez (Pataca-Grossa) i Josep Bernat i Baldoví (El sueco)» (GEC: «El Mole»).

23 També, entre altres, Josep Maria Bayarri i Hurtado (1886-1970), Joan Gil-Albert (1904-1994) i Manuel Sanchis Guarner (1911-1981).

24 «Valencia (ES) Real colegio San Joaquín y parroquia San José de Calasanz».

SCRIPTA, Revista internacional de literatura i cultura medieval i moderna, núm. 6 / desembre 2015 / pp. 60 - 99 ISSN: 2340-4841 · doi:10.7203/SCRIPTA.6.7824 
Lluís Roda. La continuïtat «bioliterària» al País Valencià: de Carles Ros a Carles Salvador (o de Gregori Maians a Vicent Andrés Estellés, passant per Teodor Llorente)

\begin{abstract}
Después de la invasión francesa la vida literaria del colegio tomó otro rumbo: la personalidad de escolapios como J. Arolas, V. Boix, P. Pérez, G. Serrano, J. Vicente y otros puso en marcha un movimiento literario vernáculo y este círculo escolapio nutriría después las filas de la Renaixença valenciana. ${ }^{25}$ Fueron, efectivamente, alumnos del colegio, entre otros, los renaixentistes A. Cabrelles, F. Bahamonde y Sessé, J. Balader, A. M. Ballester, J. Bernat i Baldoví, J. Bodría, J. B. Burguet, A. Codonyer, J. Fambuena, F. Fayos, R. Ferrer i Bigné, J. Labaila, C. Llombart, M. Millas, C. Pasqual i Genis, J. Peyró i Dauder, F. Pizcueta, V. W. Querol, A. Roig Civera, T. Villarroya. Muchos de éstos estuvieron en contacto directo con los escolapios románticos y liberales citados, comulgaron con sus ideas y aun colaboraron con ellos.
\end{abstract}

A més dels esmentats, hi ha també Benet Altet i Ruate (1827-1893), que escriu Déu i lo món (1854, un llibre corregit i augmentat el 1858) i Sen Vicènt (1855, un extens poema èpic guanyador del certamen literari organitzat per la Societat Econòmica d'Amics del País, que en celebrava el quart centenari de la canonització, i que fou publicat com a llibre ${ }^{26}$ o la composició «A la Santíssima Verge dels Desemparats» (1867). Benet Altet fou deixeble d'Aparisi i Guijarro (1815-1872), com també ho va ser Teodor Llorente (1836-1911). ${ }^{27}$

Sorprén molt, doncs, l'afirmació de Llorente, que Fuster, més tard, usarà com a argument (1956: 27-28). Recordem-la de nou:

La Renaixença valenciana serà un fillol de la Renaixença del Principat, i no, com Ros i Galiana podien fer preveure, una prolongació del moviment local setcentista innervat pels clàssics. «En el primer tercio del presente siglo -escriu Llorente a Rubió i Ors en 1887- no conozco ninguna persona de algún viso o regular ilustración que haya escrito en valenciano.»

Però Fuster s'adona que les Escoles Pies de València són un referent ineludible també per copsar la nostra Renaixença. Són clars els vincles com a professors, com a alumnes, o les dues coses, de la major part dels protagonistes de la generació anterior al poeta de Llibret de versos. Diu Fuster (1956: 30):

Un nucli literari poderosament viu de la València vuitcentista fou el de les Escoles Pies. Quant a la irradació ciutadana, l'èxit favorable del Romanticisme al País Valencià correspon a un grup d'escolapis, batallador i atent a les novetats literàries estrangeres. Jaume Vicente, Joan Arolas, Pasqual Pérez i Vicent Boix, tots ells professos i professors en l'orde calassancià, representen l'avançada de les idees romàntiques entre nosaltres. [...] Per comprendre el paper que juguen en el desenvolupament de la vida literària local, recordarem que, essent les Escoles Pies el

25 Aparisi i Guijarro (1815-1872) recordarà Jaume Vicente com el mestre decisiu en la conformació de la seua vocació literària, també ho fa Rafael Vives i Azpiroz (1813-1886).

26 Sen Vicènt. Poèma en valenciá, Imprenta de Jusep Ferrer de Orga, Valencia, 1855 [sic], 88 p.

27 Recordem que tant Antoni Aparisi i Guijarro (1815-1872) (Galindo: 12) com Rafael Vives i Azpiroz (1813-1886) reconeixen Jaume Vicente (? - 1833), de les Escoles Pies, com el mestre decisiu de la seua vocació literària. I també que tant Antoni Aparisi com Rafael Vives foren companys d'estudis de Vicent Boix (1813-1880).

SCRIPTA, Revista internacional de literatura i cultura medieval i moderna, núm. 6 / desembre 2015 / pp. 60 - 99 ISSN: 2340-4841 · doi:10.7203/SCRIPTA.6.7824 
Lluís Roda. La continuïtat «bioliterària» al País Valencià: de Carles Ros a Carles Salvador (o de Gregori Maians a Vicent Andrés Estellés, passant per Teodor Llorente)

\begin{abstract}
centre d'ensenyança més acreditat de la València d'aleshores, per les seues aules passarien la majoria dels escriptors que després nodriran els rengles de la Renaixença. Villaroya, Llorente, Pasqual i Genís, Jacint Labaila, Fèlix Pizcueta, Ferrer i Bigné, en foren alumnes. Manuel de Montoliu afirma que el barceloní Arolas i el valencià Pérez havien donat a conèixer, a València, els poemes del Gaiter del Llobregat. ${ }^{28}$
\end{abstract}

Recordem que Antoni Maria Peyrolon (a. 1813 - d. 1837) havia publicat el 30 de maig de 1830, al Diario de Valencia, «En los dies del nostre rei Fernando» (Simbor 1980: 90-93). Es tracta d'un «escriptor semidesconegut» (Simbor 1988a: 11). Amb tot, hem trobat una dada sobre Antoni Maria Peyrolon que podria servir per obtenir més informació biogràfica d'aquest poeta pioner de la Renaixença catalana general, el qual ens apareix, l'any 1837, estretament vinculat amb Thomas Trenor (Pons / Serna: 48):

\begin{abstract}
A l'estiu de 1837 [Thomas Trenor] el veiem apoderant el factor de sa casa de comerç [càrrec equivalent a «encarregat» $\mathrm{o}$ «gerent»], Antonio María Peyrolón, perquè en nom seu, i com «uno de los empresarios de la limpia del puerto», puga «dirigir la empresa de los buques vapores existente en el Puerto para la expresada limpia».
\end{abstract}

Els autors de l'article també suggereixen un possible parentiu entre J. M. Peyrolón i Antoni Maria Peyrolon (Pons / Serna: 52):

El destinatari torna a ser Villiers [George Villiers, l'ambaixador britànic a Madrid] i el to és semblant, encara que s'aplaudeixen també els bons oficis del vicecònsol, J. M. Peyrolón, potser emparentat amb Antonio María Peyrolon, el factor de la seua societat mercantil.

Precisament, serà un nét d'aquest immigrant irlandés Thomas Trenor Keating (Dublín 1795/1798 València 1858) el poeta més jove que clourà Poetes valencians contemporanis (1908), una antologia feta probablement per Teodor Llorente, publicada per L'Avenç a Barcelona: Leopold Trenor i Palavicino (Madrid 1870 - València 1937), que fou president de Lo Rat Penat entre 1908 i 1910 (Roda 2011a, 2011c). Més encara, devem al seu germà Tomàs Trenor i Palavicino, I Marqués del Túria (València 1864 - Madrid 1913), que aleshores era el president de l'Ateneu Mercantil de València, la idea i l'impuls de l'Exposició Regional de València de 1909, en el transcurs de la qual Llorente rebé l'històric homenatge, que clou el cicle de la nostra Renaixença (1930-1909).

La informació sobre Antoni Maria Peyrolon que fins ara disposàvem (J. P. Fuster 1830: 507) conté un parell d'errors, sens dubte tipogràfics.

El llibre Plácido y Blanca ó Las Batuecas, de la comtessa de Genlis, traduït per D. A. P. (Antoni M. Peyrolon) del francés al castellà, fou publicat l'any 1826 i no el 1820 (llevat que la data de 1826, que hem vist impresa, siga la d'una reedició del volum i no, com creiem, la data de la primera edició

28 Fuster no esmenta ni Rafael Vives Azpiroz (1813-1886) ni Antoni Aparisi i Guijarro (1815-1872), entre els estudiants.

SCRIPTA, Revista internacional de literatura i cultura medieval i moderna, núm. 6 / desembre 2015 / pp. 60 - 99 ISSN: 2340-4841 · doi:10.7203/SCRIPTA.6.7824 
Lluís Roda. La continuïtat «bioliterària» al País Valencià: de Carles Ros a Carles Salvador (o de Gregori Maians a Vicent Andrés Estellés, passant per Teodor Llorente)

d'aquesta traducció de Les Battuécas que la comtessa de Genlis va publicar el 1816. Mentre que el sonet en castellà «á la muerte de D. Simon de Rojas Clemente» [sic] (1777-1827) aparegué al Diario de Valencia el 5 d'abril del 1827 i no del 1817, aquest darrer error ja havia estat notat (Simbor 1980: 93), però no l'altre. Segons J. P. Fuster i Taronger, Antoni Maria Peyrolon era: «Natural de Valencia, y oficial escribiente único de la Administracion del Real Estado de la Albufera, joven que con facilidad cultiva las musas», el qual també escriu «Poesías para la Real Maestranza de esta Ciudad á la venida de los Reyes nuestros Sres. en 1827».

I recordem també que el bibliòfil Vicent Salvà (1786-1849), a París, l'any 1831, havia escrit el poema «Lo somni» per a Vicenta Bertran de Lis: «cuyo matrimonio con Pedro, hijo de Vicente Salvá, se frustró en los años 30 en París» (Ardit), que era filla de Vicent Bertran de Lis, un dels caps del liberalisme valencià exiliat a París, com Salvà, la qual confeccionava un àlbum «on trobem poesies dels romàntics espanyols exiliats de més renom» (Simbor 1988a). «Lo somni» fou publicat per primera vegada l’any 1940 pel besnét (Salvà).

[...] tropecé un día con una carta de mi bisabuelo don Vicente Salvá. escrita [sic] en París en Mayo de 1831 y dirigida a su esposa doña Josefa Malleu, mi bisabuela, residente a la sazón en Londres. [...] Decía éste en su carta, que a ruegos de una señorita de la familia de Bertrán - debe de ser la familia de Bertrán de Lis- había compuesto un juguete en valenciano para un álbum -cosa muy de época- que dicha señorita poseía y en el que habían escrito poesías Martínez de la Rosa, Saavedra -el que después fué Duque de Rivas-, Gorostiza y otros vates de aquel tiempo. Y le acompañaba una copia, de mano suya, para su conocimiento. ¿Qué habrá sido de aquel álbum? Han pasado más de cien años desde aquel entonces y seguramente de él no quedará rastro. $[\ldots]$

I el poema inclòs a la carta, publicat l'any 1940 pel besnét, hi apareix perfectament datat: «Ho feu en Paris, lo 1er. jorn de maig del any 1831» [sic].

El polític liberal, poeta i llibreter, retornà a València de París l'any 1834, després d'haver viscut també a Londres (1824-1830), on fundà una llibreria al núm. 124 de Regent Street.

Pasqual Pérez compartia tertúlia amb el pare de V. V. Querol, que li mostrà uns manuscrits primerencs del fill, en vistes dels quals Pérez va vaticinar que havia de ser un gran poeta i prengué pel seu compte l'educació literària del poeta novell, aconsellant també el seu ingrés al col legi de les Escoles Pies, el més important de la València d'aleshores: «Este fue mi querido y verdadero maestro [en referència a Pasqual Pérez]》, afirmà el poeta de Rimes catalanes en un article en forma de carta a Llorente publicat a l'Almanaque de Las Provincias per a 1887 («Mis primeros versos», p. 65). Els joves Llorente i Querol s'havien conegut a la Universitat de València: «En l'any 1853 [Querol] va triomfar en un concurs poètic entre alumnes de la Universitat; hi coneix Llorente $\mathrm{i}$ altres poetes estudiants, que abundaven aleshores i escrivien tots en castellà» (Guarner 1980: 14-15). I per bé que les primeres poesies en català que tenim datades de Querol són de 1859 («A l’esperança», «Què serà», «A la fe»), sembla que ja s'havia iniciat en la lírica en català entre el 1856 i el 1857 amb una oda «A Valensia» [sic], avui perduda (Guarner 1980). 
Lluís Roda. La continuïtat «bioliterària» al País Valencià: de Carles Ros a Carles Salvador (o de Gregori Maians a Vicent Andrés Estellés, passant per Teodor Llorente)

Pel que fa a Llorente, als dívuit anys, ja s'havia estrenat com a dramaturg al Teatre Principal de València amb l'obra en castellà Delirios de amor, arran de la qual conegué, aquell mateix 1854, Antoni Aparisi i Guijarro (1815-1872): «la literatura francesa la conocí gracias a Aparici [sic] Guijarro, que debía ser tan famoso literato como célebre orador fue, pues desde que murió Arolas hasta que nació Wenceslao Querol, Aparisi fue el mejor poeta valenciano» (Roca 2013a: 117). ${ }^{29}$ Com en Querol, també trobem en Llorente el mestratge de Pérez: «sota el mestratge d'autors ja consagrats com ara Antoni Aparisi i Guijarro i Pasqual Pérez i Rodríguez» (Roca 2004: 25).

Quan Marià Aguiló (1825-1897) va arribar a la Universitat de València a treballar de bibliotecari per l'abril de 1858, el de Palma no havia fet encara els trenta-tres anys. Però en aquell moment, la coneixença entre Llorente i Querol i la vocació literària d'aquests eren ja un fet. Llorente i Querol tenien respectivament vint-i-dos i vint-i-un anys, aleshores. Al número del 15 de juliol de 1858 de la revista Las bellas artes, Llorente publica un llarg poema en català de deu estrofes: «A mon amich el poeta D. Antonio Aparisi y Guijarro». ${ }^{30}$ Abans, als dènou anys, l'any 1855, Llorente ja havia escrit «L'amor del poeta», dotze estrofes encapçalades per una citació d'Ausiàs March; l'any següent, el 1856, escriu «Ple de suspirs el pit» [sic], els dos poemes van ser publicats pel fill pòstumament (Poesies valencianes, 1936). L'any 1857, al periòdic El conciliador, dirigit per Pasqual Pérez, Llorente havia publicat «Mon trist caminar», «Aparició» $\mathrm{i}$ «La poesia»: «El docte humanista D. Pasqual Pérez, pare escolapi exclaustrat, company de Arolas y de Boix, les publicà en un periòdich polític que dirigia», segons explicà el mateix Llorente a Llibret de versos (1885), i afegia: "presentant aquelles composicions y altres de D. Benet Altet i Ruate com una esperansa per al renaiximent de les lletres llemosines. La idea de versificar en valencià me la inspirà la lectura del Gayter de Llobregat, del Sr. Rubió y Orts». I datat a «València, 7 de jiner de 1858» [sic], hi ha el poema «iVent-i-dos anys!», però aquest poema va ser publicat quatre anys més tard (Roca 2013a: 97-120). La vida literària del jove Llorente, durant l'època universitària, discorregué al voltant de les Escoles Pies i d'El Liceu Valencià, on va rebre la influència d'escriptors com ara Vicent Boix i Josep Maria Bonilla» (Roca 2004: 25).

Bernat i Baldoví (1809-1864) i Vicent Boix (1813-1880) van ser incorporats per Víctor Balaguer (1824-1901) a Los trobadors moderns poc després (1859-1860).

Vicent Boix havia col laborat, com a corresponsal de València, amb Víctor Balaguer a La Corona de Aragón (1854-1856); a Saragossa hi havia Jerónimo Borao: «òrgan d'una aliança entre els elements progressistes avançats i autonomistes dels territoris de l'antiga corona catalanoaragonesa [...]. Fou aviat acusat de separatisme» (GEC: «La Corona de Aragón»). Abans, Boix i Balaguer ja s'havien conegut a València l'any 1845 (Roca 1997, 2007a: 173-174), d'aquell contacte tenim uns fruits literaris recollits a la revista El Fénix, però l'escriptor de Barcelona «fins 1857 no faria el canvi de llengua». Boix va ser mantenidor dels Jocs Florals de Barcelona l'any 1877, tres anys abans de morir.

29 Entrevista a Teodor Llorente. Revista Por esos mundos, núm. 191, 1910, pp. 941-942.

30 Aquest poema que Teodor Llorente publicà el 1858 a la revista Las Bellas Artes no l'inclogué mai en cap volum posterior, i fou reeditat pòstumament pel seu fill a Poesies valencianes (1936).

SCRIPTA, Revista internacional de literatura i cultura medieval i moderna, núm. 6 / desembre 2015 / pp. 60 - 99 ISSN: 2340-4841 · doi:10.7203/SCRIPTA.6.7824 
Lluís Roda. La continuïtat «bioliterària» al País Valencià: de Carles Ros a Carles Salvador (o de Gregori Maians a Vicent Andrés Estellés, passant per Teodor Llorente)

Tot i que Aparisi i Guijarro va escriure tota la seua poesia en castellà, per l'abril de 1842 féu un poema de títol ben revelador: «Á D. Tomás Villarroya, autor de una hermosísima cancion en lengua valenciana á la Sra. Doña Antonia de Montenegro», la primera estrofa del qual diu (Aparisi 1873: 229):

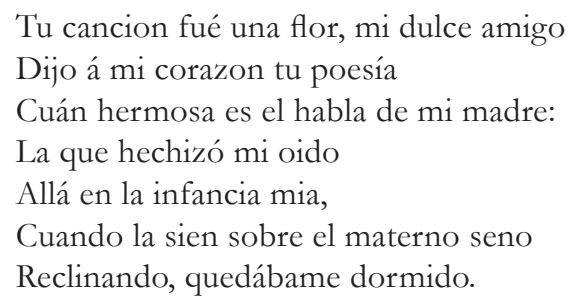

Entre les poesies d'Antoni Aparisi i Guijarro, hi ha també les titulades: «A D. Jaime I, Rey de Aragon: conquistador de Mallorca y de Valencia, con motivo de la fiesta secular celebrada en esta ciudad en el año 1838» (Aparisi 1873: 312) i «A San Vicente Ferrer, en la fiesta del cuarto siglo de su canonizacion: año 1855» (Aparisi 1873: 315). Aquest poema fou un dels que Vicent Boix, com a cronista de la ciutat de València, va recollir i editar, per encàrrec de la corporació, amb motiu de l'efemèride, sota l'epígraf Corona poética a San Vicente Ferrer en el cuarto siglo de su canonización. Set d'aquells poetes convidats, entre els quals hi havia uns joveníssims Llorente i Querol, van optar per fer servir el català en les seues composicions. Foren Joan Baptista Marqués i Aucher, Joan Antoni Almela, Benet Altet i Ruate, Pasqual Pérez i Rodríguez, Josep Manuel Blat i Soto -que només comptava amb quinze anys-, Maria Orberà i Carrion, i Frederic Blasco i Martínez (Simbor 1988a: 12). Sens dubte, es tractava d'un motiu religiós però també emblemàtic: «Se acuerda invitar á los pueblos de la antigua corona de Aragon, para que envien sus representantes en la próxima festividad» (Fiestas que en el siglo IV de la canonización de San Vicente Ferrer se celebraron en Valencia. Relación escrita por Don Vicente Boix, Cronista de la misma ciudad, y publicada á espensas de la Sociedad Económica de Amigos del País. Valencia: Imprenta de José Rius - 1855, p. 62). Potser ens interessa també recordar que Boix havia conegut Chateuabriand i Victor Hugo a París l'any 1838. Aquell mateix 1855, Marià Suay i Josep Bernat i Baldoví opten pel català per fer la seua contribució a l'Album poético a la terminación del ferro-carril del Grao de Valencia a Játiva, dedicado al Señor Don José Campo, concesionario, Director-gerente y fundador de la Sociedad creada para tan laudable objeto (Simbor 1988a: 12), sense que el tribut a aquesta màquina de l'era industrial puga concebre's com una reminiscència medieval, òbviament.

Aparisi sembla que havia guanyat un certamen literari als dotze anys: «Un suceso honroso principió á labrar su reputacion: tendría sobre doce años y en público certámen se le adjudicó uno de los premios de no sé qué sociedad: paréceme que era la de Amigos del País» (Galindo: 14-15). Abans, el biògraf ho explica (Galindo: 12-13):

Apenas tuvo edad Tonico (1) [Nota a peu pàgina de Galindo: «En valenciano, diminutivo de Antonio»], pusiéronle á estudiar latin en el colegio andresiano de las Escuelas Pias [...] Tambien enseñaban en la escuela á versificar; en latín por supuesto; pero sin que desdeñasen las musas 
Lluís Roda. La continuïtat «bioliterària» al País Valencià: de Carles Ros a Carles Salvador (o de Gregori Maians a Vicent Andrés Estellés, passant per Teodor Llorente)

de Castilla, ni a los poetas en ciernes de quienes el P. Jaime Vicente recibía las confidencias, contenía las rivalidades, corregía las composiciones, juzgaba del mérito respectivo, y vez hubo en que, para animarlos, les leia versos suyos, no siempre superiores á los de sus discípulos.

També reconeix aquest mestratge de Jaume Vicente, el dramaturg valencià Rafael Vives i Azpiroz (1813-1886):

Era un temps en què existia rivalitat entre el col legi dels jesuïtes, que només acollia nobles, i l'Escola Pia, que no era tan elitista. Les famílies de les classes acomodades que escollien aquesta segona opció ingressaven els seus fills com a col legials interns en el Seminario Andresiano, però, paral lelament, l'orde calassancià educava tota la resta de la població escolar en les escoles públiques gratuïtes. [...] la institució escolàpia, que ell mateix [Rafael Vives] qualifica de popular i democràtica. Tingué com a company d'estudis Vicent Boix i com a professor, Jaume Vicente, que li corregí els primers versos i a qui confessa deure el seu amor a les lletres. Tots dos personatges pertanyien al nucli escolapi difusor del Romanticisme a València» (Garcia 2000: 59).

I no havent fet encara els catorze anys Aparisi coneix Salvà (Galindo: 16-17):

Un deseo vehementísimo le aquejaba: tener un libro de versos; los fondos de su madre no eran para tanto; prometiósele al fin como premio, si adelantaba en sus estudios, y llegó, que todo llega, el dia en que le acompañase á casa de Salvá, librero y literato de gran reputacion en Valencia [...]. No tardó mucho en realizar sus ilusiones infantiles: sobre catorce años tenia [...].

Probablement, les anades i tornades de Vicent Salvà a València, de grat o per força, degueren ser perillosament freqüents, des de Castella, Mallorca, Itàlia, França o Anglaterra. Serveixen per ressaltar una València vuitcentista convulsa, activa i al dia, connectada directament amb Londres i París. I amb una actitud lingüística no sempre servil, per bé que condicionada, com bé mostra aquesta dècima en espanyol, afegida junt amb unes altres composicions en català en la reedició de 1847 del milacre vicentí La font de Llíria, una publicació de l'any 1822 (Fuertes):

\footnotetext{
El que ignore el valenciano, no se meta a decidir, si en nuestro común decir hablamos o no en cristiano; que este idioma liso y llano, tiene su estudio profundo, y es en gracias más fecundo que el castellano, el francés el alemán y el inglés, y cuantos hay en el mundo.
} 
Lluís Roda. La continuïtat «bioliterària» al País Valencià: de Carles Ros a Carles Salvador (o de Gregori Maians a Vicent Andrés Estellés, passant per Teodor Llorente)

De fet, fou Pere Salvà i Mallén (1811-1870), fill de Vicent Salvà i Pérez (1786-1849), llibreter i bibliògraf com son pare, a qui havia seguit a l'exili l'any 1824, i que havia estat també l'encarregat de la llibreria de Londres entre 1830 i 1834, i de la de París a partir de 1834, i havia tornat a València l'any 1847, qui anys més tard, el 1858, va tenir la idea de convidar Marià Aguiló, després d'haver fet gestions fructíferes a títol personal amb el rector, perquè ocupara la vacant a la Universitat literària de València de la plaça de bibliotecari, que s'havia produït per mort sobtada, per tal de ferse càrrec d'un fons tan important com aquell. Els motius, tècnics i erudits, indirectament palesen la clara consciència del fill de Vicent Salvà, que continuava el llegat de son pare: «un mentor con cuyo auxilio únicamente podria tirar adelante en el maremagnum de mi catálago» (aquest valuosíssim catàleg va ser publicat pòstumament, el 1872: Catálogo de la biblioteca de Salvá, escrito por D. Pedro Salvá y Mallen, però aquest fons tan extraordinari, una vegada morts el pare i el fill, aviat fou malvenut i es va veure dispersat).

Pere Salvà, per tal de convéncer Marià Aguiló, en aquella mateixa carta de l'11 de març de 1858, li fa saber: «Universidad literaria, donde V. sabe hay una de las mejores librerías de España, en ella está el Tirant lo Blanc, Obres é Trobes á laor de la Verge, muchos libros de caballerías, obras del siglo XV y los célebres códices del Duque de Calabria» (Tomàs 2012: 34-35). Un mes després arribava Aguiló a València on s'estigué laboralment fins a juny de 1861. Uns anys programàticament decisius en molts aspectes. ${ }^{31}$ El 9 de febrer de 1859 Aguiló escriu a son pare: «He recibido muestras de deferencia de los chicos o literatos de más provecho de por aquí. Poco a poco voy conociendo esto mejor que antes.» I el 9 de març en una carta a Bartomeu Muntaner declara el seu proselitisme: «Predico el catalanismo y hago numerosas conversiones» (37). Llorente i Querol aleshores tenien vint-i-dos i vint-i-un anys respectivament. Sens dubte, aquest mallorquí exercí una influència tal vegada no única però sí decisiva, com palesarà, anys després, la dedicatòria de la primera edició de Llibret de versos (1885) de Llorente.

Teodor Llorente va rebre, directament o indirectament, i ens ha transmés, tot simbolitzant-la inconscientment o conscientment, la torxa aparentment bicèfala de l'etapa inicial (1830-1859) de la nostra Renaixença, aquella que amb feliç contundència literària (amb un paral lelisme eloqüent i una eloqüència paral lela), al seu torn, havien recollit, el monàrquic «En los dies del nostre rei Fernando» d'Antoni Maria Peyrolon (1830) i el liberal «Lo somni» de Vicent Salvà (1831), tots dos representatius de l'avançada modernitat romàntica europea. Reflecteixen la singularitat del seu moment i són la manifestació d'una actitud i d'una continuïtat esforçades, no exemptes de contradiccions.

31 Aquell treball de Marià Aguiló, arran del qual ja havia vingut a València en alguna ocasió i conegut Pere Salvà, fou premiat a Madrid, però no va veure la llum fins l'any 1923: Catálogo de obras en lengua catalana impresas desde 1474 hasta 1860 (Aguiló 1977). 
Lluís Roda. La continuïtat «bioliterària» al País Valencià: de Carles Ros a Carles Salvador (o de Gregori Maians a Vicent Andrés Estellés, passant per Teodor Llorente)

El final d'aquesta etapa el marca la celebració, l'any 1859, al Paranimf de la Universitat i amb el suport de l'Ajuntament de València, d'uns Jocs Florals per tal de commemorar el 400 aniversari de la mort d'Ausiàs March, tot un signe.

Rubió i Ors (1858: 14-15), pel desembre de 1858, dóna notícia d'aquest projecte:

\begin{abstract}
[...] y puix que casi tot lo mitj dia de la Fransa treballa per fer reviurer la poesia y lo idioma, que se parlava en sos jochs florals tan famosos [...] y puix que fins Valencia, recordantse de son estimat Conquistador, sembla que se disposa també á cantar sos recorts en la llengua en que escrigué En Jaume I sa crónica, ¿perqué no havem d'esperar -y ara mes que may- que naixe un jorn lo sol que illumine en tots los que foren dominis de aquell gran rey, una poesía tan original y diferent de la de les nacions que nos rodejan, com lo nostre carácter, nostre geni, nostre clima y la llengua y la historia nostras ho son de las de aquellas?
\end{abstract}

Segons Llorente: «naixqué ensemps en València i en Barcelona; mes se deu dir que fon un català, l'entusiasta D. Marian Aguiló, qui primer la soltà en la pàtria d'Ausiàs March» (Roca 2004: 29). Concorregueren Víctor Balaguer i un jove Teodor Llorente de vint-i-tres anys amb un poema titulat significativament «La nova era». Tots dos resultaren guanyadors. Coneixem els mantenidors d'aquells primers Jocs Florals (Tomàs: 41-42):

\begin{abstract}
A Valencia [...] cabe en muy honrosa parte la iniciativa de este movimiento literario: suscitada la idea de los Juegos Florales en la Academia literaria y artística, fueron nombrados para llevarla a objeto, como Jueces Mantenedores, los distinguidos literatos D. Antonio Aparisi y Guijarro, D. Manuel Benedito, D. Pascual Pérez y Rodríguez, D. Vicente Boix, D. Miguel Vicente Almazán, D. Mariano Aguiló y D. Peregrín García Cadena. El Excelentísimo Ayuntamiento acogió con galante benevolencia la invitación de honrar el poético certamen con su protección y su nombre [...] para premiar a los autores de poesías en la lengua provenzal-catalana, vulgarmente llamada lemosina, a Ausias March y a un tema religioso, y el que lo fuese de otra castellana sobre un hecho glorioso de la historia de Valencia.
\end{abstract}

Les relacions amb escriptors de Catalunya s'anaven a enfortir i a consolidar durant la segona i la tercera etapes de la Renaixença: 1859-1874, 1874-1909. Però no volem deixar de recordar, ${ }^{32}$ abans de cloure aquest període, anterior a la irrupció de Teodor Llorente (1836-1911) a partir de 1859, els quatre poemes de Tomàs Villarroya (1812-1856), publicats entre el 1840 i el 1841, l'ordre cronològic d’aparició dels quals és: «Canzó. Per a el Àlbum de la Senyora Antonia de Montenegro», publicat el 23 de gener de 1840 al Diario Mercantil de Valencia, que Pasqual Pérez fundà i dirigí fins 1844; «Canzó. A la mort del pintor valencià D. Antoni Cavana», publicat el 8 d'agost de 1840 al mateix diari; «Canzó», publicat a la revista El Liceo Valenciano al número de gener de 1841, i «Adéu! A la Sra. Doña Antonia de Montenegro», publicat a la mateixa revista al número de setembre d'aquell 1841. Els dos primers van tornar a aparéixer publicats a les planes d'El Liceo valenciano, al número d'abril de 1842, el primer, i al número de juliol de 1841, el segon.

32 Usem principalment informació de Simbor (1988a).

SCRIPTA, Revista internacional de literatura i cultura medieval i moderna, núm. 6 / desembre 2015 / pp. 60 - 99 ISSN: 2340-4841 · doi:10.7203/SCRIPTA.6.7824 
Lluís Roda. La continuïtat «bioliterària» al País Valencià: de Carles Ros a Carles Salvador (o de Gregori Maians a Vicent Andrés Estellés, passant per Teodor Llorente)

Recordem també el poema de Pasqual Pérez (1804-1868): «A Sa Majestat la Reina Donya Maria Cristina», publicat al Diario Mercantil de Valencia el 15 de març de 1844. I el poema de Josep Joaquim Agulló, comte de Ripalda (1810-1876), publicat a El Fénix el 29 de novembre de 1846: «Poesia llemosina al casament real». Pasqual Pérez escriu el 1849: «Al mal lograt poeta Don Juan Arolas», encara que no es va publicar fins al 1869. El 25 de febrer de 1852, el Diario Mercantil de Valencia publica el poema de Josep Maria Bonilla (1808-1880): «A la memòria del ilustre Asara - El sigle XIX», que ja era acabat el 2 de setembre de 1850. El 22 de març de 1852 s'inaugura el primer tram del ferrocarril, del Grau a València, que el 20 de desembre de 1854 va arribar fins a Xàtiva. S’imprimí -i calculem, doncs, que es repartí- un poema d'un joveníssim Salvador Estellés (18391861), que aleshores devia fer uns quinze anys: «Himne al ferro-carril del Grau de Valensia a Xàtiva» [sic], poema que fou recollit després a la revista El Rubí en l'homenatge pòstum que se li reté el 3 de novembre de 1861, arran del traspàs primerenc del jove col laborador. ${ }^{33} \mathrm{El} 30$ d'abril de 1854, la revista El Cisne, dirigida per Josep M. ${ }^{a}$ Bonilla, publica el poema «Béns del món», del baró d'Andilla. ${ }^{34}$

Als quals, a partir de 1855, seguiren molts altres poetes i poemes que ja han estat esmentats més amunt. $^{35}$

En definitiva, com bé diu Simbor (1988a: 11):

\begin{abstract}
Només entrar a la dècada dels trenta és notori un moviment progressivament creixent en l'ús culte de la llengua fins als darrers anys cinquanta, en què ja apareixien públicament les figures considerades cimeres de la Renaixença Valenciana: Llorente i Querol.
\end{abstract}

Abans, Simbor ens havia dit (1988a: 10):

\begin{abstract}
D'altra banda, jo mateix m'he dedicat a estudiar aquells precedents amb tanta facilitat oblidats per Llorente i els resultats no poden ser més interessants. Així descobrim l'existència d'un fil conductor sense interrupcions des de finals del xviII, fita inicial de l'estudi, fins a la consagració oficial de la Renaixença, l'any 1859.
\end{abstract}

Tanmateix, V. Salvador (2001: 107), en relació a l'intent esforçat de Carmel Navarro i Llombart, deia: «una trajectòria prerenaixentista que Constantí Llombart, en Los fills de la morta-viva volia retrotraure fins al notari Carles Ros».

33 Simbor (1988a: 11-12) el data el 1952, «fet per l'autor amb motiu de la inauguració del primer tros del trajecte, de València al Grau».

34 Creiem que deu ser Antoni Garcés de Marcilla, baró d'Andilla (1797-1883).

35 Trobareu informació detallada sobre aquests i altres poemes d'aquest període inicial a Simbor (1980, 1988a).

SCRIPTA, Revista internacional de literatura i cultura medieval i moderna, núm. 6 / desembre 2015 / pp. 60 - 99 ISSN: 2340-4841 · doi:10.7203/SCRIPTA.6.7824 
Lluís Roda. La continuïtat «bioliterària» al País Valencià: de Carles Ros a Carles Salvador (o de Gregori Maians a Vicent Andrés Estellés, passant per Teodor Llorente)

Però potser Carmel Navarro: Constantí Llombart (1848-1893), en contra del que la citació de Salvador sembla suggerir, no anava tan desencaminat.

\section{De Carles Ros (1703-1773) a Constantí Llombart (1848-1893)}

Josep Rodríguez (València 1630 - 1703), frare trinitari, és l'autor d'una Biblioteca valentina, que conté més de set-cents autors, els primers plecs de la qual foren publicats el 1695 i la redacció de la qual era ja acabada el 1703, l'any de la seua mort. Tanmateix, l'edició restà blocada per un superior de l'orde. El trinitari felipista Ignasi Savalls i Peres (1656-1746) hi afegí una Adición en el moment de ser publicada el 1747, quan ja s'anunciava Escritores del reyno de Valencia de Vicent Ximeno (València 1691-1764). De la mateixa dècada que Vicent Ximeno són Josep Teixidor (el Grau, València 1694 - València 1775) i Gregori Maians i Siscar (Oliva 1699 - València 1781). ${ }^{36}$

Josep Rodríguez (València 1630 - 1703) va nàixer quasi al mateix temps que el matemàtic, astrònom i cosmòleg Bernat Josep Saragossà i Vilanova (Alcalà de Xivert 1627 - Madrid 1679). El bibliògraf Josep Rodríguez pertanyé al cercle preil lustrat valencià de Josep de Castellví i d'Alagon (1653-1722), comte de Cervelló i primer marqués de Vilatorques (1680), qui aplegà més de 7.000 volums i ajudà Rodríguez en l'elaboració de la Biblioteca valentina. Entre aquells capdavanters novatores valencians, renovelladors d'idees i de pràctiques científiques, que tenien Saragossà com un precedent, alguns dels quals ja mantenien reunions si més no des del 1686, hi havia el científic i filòsof Tomàs Vicent Toscà i Mascó (València 1651 - Valencia 1723), de qui Maians (1699-1781) escrigué la biografia, ${ }^{37}$ els matemàtics Baltasar Íñigo (València 1656 - València 1722) i Joan Baptista Coratjà (València 1661 - València 1741), el metge Joan de Cabriada (València 1665 - 1714) i Manuel Martí i Saragossà (Orpesa 1663 - Alacant 1737), conegut també com el degà Martí (o el degà d'Alacant), aquest darrer format en l'il luminisme i bibliotecari del cardenal Sáenz de Aguirre a Roma, on tingué contacte directe amb els jansenistes i d'on tornà el 1696, i de qui Maians (1699-1781) també escrigué la biografia. Martí va influir en la historiografia valenciana i, a més de Maians, en fou deixeble l'humanista Josep Manuel Minyana i Estela (València 1671 - València 1730), entre altres.

Però entre el 1630, any de naixement de Josep Rodríguez -l'autor de la Biblioteca valentina-, i el 1691, any de naixement de Vicent Ximeno i Sorlí (València 1691 - 1764) -l'autor d'Escritores del reyno de Valencia-, van nàixer també, a més dels que ja han estat esmentats: Josep Carbó i Climent (València 1630 - ?), Crescenci Cerveró (València 1633 - 1708), Vicent Carbonell (Alcoi, s. XVII - d. 1690), Marc Antoni Ortí i Moles (València 1647 - 1687), Alexandre Arboreda (València 1650 - 1698), Josep Ortí i Moles (València 1650 - 1728), Pere Joan Bogart i de Gomera (València, ? - Xàtiva 1707), Isidor Planes (Puçol s. XVII - València 1729), Joan Baptista Aguilar (? - 1714), Francesc Figuerola i Espècies (València 1654 - 1694), Josep Llorenç i del Clavell (Castelló de la Plana s. XVII - 1734), Ginés Campillo de Bayle (Elx a. 1669 - València 1696), Pere Vicent Sabata i Grifolla (Sant Mateu 1662

36 Veg. Bas (2002) i Seguí (2005).

37 Vita Thomae Vicenti Toscae (1754).

SCRIPTA, Revista internacional de literatura i cultura medieval i moderna, núm. 6 / desembre 2015 / pp. 60 - 99 ISSN: 2340-4841 · doi:10.7203/SCRIPTA.6.7824 
Lluís Roda. La continuïtat «bioliterària» al País Valencià: de Carles Ros a Carles Salvador (o de Gregori Maians a Vicent Andrés Estellés, passant per Teodor Llorente)

- 1733), Salvador Perpinyà i Perpinyà (Elx 1662 - 1728), Jacint Segura (Alacant 1668 - València? 1751), Francesc Sales (Catí 1668 - València 1736), Jacint Segura (1668-1751), Josep Vicent Ortí i Major (València 1673 - ? 1748), Carles Gassulla d'Ursino (Morella 1674 - 1745), Antoni de Peguera i Aimeric (Barcelona 1681 - València 1707), Cristòfor Coret i Peris (Alboraia 1683 - València 1760).

Van nàixer en el primer terç del s. XVII, o bé en algun moment del segle, per bé que ens manquen dades en algun cas, els següents, entre els no esmentats encara: Ceferí Clavero i Lloris (València d. 1607 - 1670), Nicolás Antonio (Sevilla 1617 - Roma 1684), Francesc Gavaldà (València 1618 1686), Llorenç Mateu i Sanç (València 1618 - Madrid 1680), Josep Pardo de la Casta (València 1618 1698), Isidor Mateu i Sanç (València 1620 - 1687), Josep Vicent de l'Olmo i Conca (València 1620 - 1696), Gaspara de la Figuera i Cubero de Monforte (Olocau de Carraixet 1623 - ? 1670), Antoni de Cardona-Borja i d'Alagó (València 1623 - Madrid 1694), Gaspar-Blai Arbuixec (Agullent 1623 València 1670), Francesc Mulet (Sant Mateu 1624 - València 1675), Joan Baptista Ballester (València 1624 - 1672), Manuel Vidal Salvador (Torreblanca - Madrid 1698), Vicent Teixidor i de Bellvís (Xàtiva), Miquel Serres i Valls (València), Baltasar Sapena i Zarzuela (València - València 1672), Joan Baptista Roig (València? - València 1650), Vicent Peres de Culla (Gandia), Cristòfor Mercader (València), Jeroni Martínez de la Vega (València), Jacint Alfons Maluenda, Antoni Bonaventura Guerau (Alcoi, ? - València 1666), Francesc Ramon Gonçales (València), Vicent Gil (? - València 1673), Vicent Ferri, Onofre Esquerdo i Sapena (València ? - València 1699), Onofre Escrivà d'Íxer i de Montpalau (València ? - València 1688), Joan Onofre Dassió i Boïl d'Arenós (València), Lluís de les Daunes (València ? - València 1673), Josep Cucarella, Narcís d'Arano i Oñate (Sant Mateu del Maestrat), Miquel Joan Bodí i Queralt (Ontinyent, ? - Villena 1636), Pau Cenedo (València, ? València 1673), Eliseu Armengol (València - d. 1688), Vicent Carbonell (Alcoi - d. 1690).

Just Pastor Fuster i Taronger (València 1761 - 1835) la llibreria del qual, fundada per son pare, fou centre de reunió del nucli il lustrat valencià, va publicar una nova Biblioteca valenciana en dos volums. El primer, aparegué el 1827: Biblioteca valenciana de los escritores que florecieron hasta nuestros dias con adiciones y enmiendas a la de D. Vicente Ximeno: contiene los autores hasta el año 1700. El segon, incorpora al títol: $y$ de los que aun viven, i especifica: contiene los autores desde el año 1701 hasta el presente de 1829. A més de Ximeno, Just P. Fuster s'ajudà també dels treballs de Francesc Cerdà i Rico (Castalla 1739 - Madrid 1800) i Juan Sempere i Guarinos (Elda 1754 - 1830). I va comptar amb la col laboració de Joan Antoni Maians i Siscar (Oliva 1718 - València 1801), germà de Gregori (1699-1781), de Marc Antoni Orellana i Mojolí (València 1731 - 1813), de Francesc Xavier Borrull i Vilanova (València 1745 - 1837) i de Jaume Villanueva i Astengo (Xàtiva 1765 - Londres 1824), germà de Joaquim Llorenç (1757-1837). ${ }^{38}$ Jaume Villanueva viatjà per terres valencianes i catalanes, sota l'encàrrec inicial de recercar i copiar documents i còdexs conservats als arxius eclesiàstics, amb el resultat d'una monumental història literària dels Països Catalans, de vint-i-dos volums (1803-1852): Viaje literario a las iglesias de España, els dotze darrers volums de la qual foren

38 Segons el DLC (Broch: 422), la Biblioteca Municipal de València conserva el manuscrit de J. P. Fuster: Noticias de los poetas de los que se hallan poesías en varios libros de fiestas que se han hecho en Valencia y Reino.

SCRIPTA, Revista internacional de literatura i cultura medieval i moderna, núm. 6 / desembre 2015 / pp. 60 - 99 ISSN: 2340-4841 · doi:10.7203/SCRIPTA.6.7824 
Lluís Roda. La continuïtat «bioliterària» al País Valencià: de Carles Ros a Carles Salvador (o de Gregori Maians a Vicent Andrés Estellés, passant per Teodor Llorente)

editats pòstumament. Els quatre primers volums corresponen al País Valencià, del cinc al vint al Principat, $i$ els dos darrers a Mallorca. ${ }^{39}$

Per tant, la connexió que Constantí Llombart (1848-1893) mostra a Los fills de la morta-viva (1883) cal entendre-la com una actualització que dóna notícia de cent cinquanta escriptors valencians dels s. XVIII i XIX, tot reconeixent un substrat poderós que ell subtitula Apunts bio-bibliogräfichs pera la bistòria del Renaiximent lliterari llemosí en València. Al final del volum afegeix cent vuitanta-nou notícies breus d'altres tants escriptors coetanis més joves. Però aquell mateix 1883 apareix un altre treball important de Josep Maria Puig i Torralva (València 1854 - 1911), deixeble de Constantí Llombart, i Francesc Martí Grajales (València 1862 - 1920), deixeble de Vicent Boix: Estudio historicocrítico de los poetas valencianos de los siglos ХИ, ХИІІ у ХИIII. El treball, que ha estat estudiat per Roca (2013b): «representa, a hores d'ara, la més pregona i sistemàtica aproximació que els escriptors de la Renaixença valenciana realitzaren a la vida i l'obra dels seus col legues de l'Edat Moderna». ${ }^{40}$ Aquests autors van tenir en compte els treballs ja esmentats de Josep Rodríguez, Vicent Ximeno i Just Pastor Fuster. ${ }^{41}$ Més encara, l'any 1927 s'edità pòstumament Ensayo de un diccionario biográfico y bibliográfico de los poetas que florecieron en el Reino de Valencia hasta el año 1700, també de Francesc Martí Grajales, el més jove. Una altra obra inèdita de Grajales: Bibliografia valenciana del siglo XVIII, no va veure la llum fins l'any 1987 (Blasco 1987). Però abans del 1927 també altres membres d'aquella generació nascuda en vida de Constantí Llombart van veure publicats els seus treballs bibliogràfics: Eduard Genovés i Olmos (1882-1922), Catàlech descriptiu de les obres impreses en llengua valenciana (19111914) i Josep Ribelles i Comín (1872-1951), Bibliografia de la lengua valenciana: o sea catálogo razonado por orden alfabético de autores de los libros, folletos... etc., que escritos en lengua valenciana y bilingüe, han visto la luz. pública desde el establecimiento de la imprenta en España hasta nuestros días (1915-1920).

39 Diu J. P. Fuster que Villanueva aplegà una col lecció de poesies catalanoprovençals que es troba a la Real Academia de la Historia de Madrid (Broch: 1072). Sobre els germans Joaquim Llorenç i Jaume Villanueva, vegeu La Parra, Llorens, Ramírez, Soler, i Tomsich.

40 Els poetes dels s. XVII i XVIII esmentats són (mostrem amb cursiva els autors dels quals no tenim dades, els altres ja figuren a l'article o bé van nàixer al s. Xvi):

s. XVII: Gaspar Aguilar, Joan Batiste Roig, Onofre Funes de Munyós, Joan Mora d’Aguirre, Vicent Ferri, Vicent Sanz, Joaquim Sala, Josep Oriola, Pere Jacint Morlà, Josep Rostojo, Marc Antoni Ortí, Josep Cucarella, Valerià Sentlí i Ulldemolins, Jeroni Martínez de la Vega, Pere Esteve i Puig, Ceferí Clavero de Falces, Eliseu Armengol, Roc Sala, Miquel Serres i Valls, Josep Carbó, Francesc Mulet, els germans Llorenç i Isidor Matheu i Sanç, Francesc Ramon Gonz̧ález, Josep Ordines i Josep Ortí Moles.

s. XviII: Carles Ros, Rosa Trincares, Alonso Carrasco, Josep Abril, Vicent Feliu, Vicent Pedró,

Joan Collado, Lluís Galiana, Bertomeu Tormo, Josep Rios, Ramon Josep Rebodilla, Pasqual Jover, Vicent Antoni Noguera i Carles Leon.

41 L’estudi de Roca (2013b) explica: «Però no només, perquè també trobem esments i referències a les obres de Vicent Mariner, Llorenç Matheu i Sans, Josep Teixidor, Francesc Pérez Bayer i Vicent Salvà; i a les cròniques de Rafael Martí de Viciana, Pere Tomich, Gaspar Escolano i Pere Antoni Beuter.»

SCRIPTA, Revista internacional de literatura i cultura medieval i moderna, núm. 6 / desembre 2015 / pp. 60 - 99 ISSN: 2340-4841 · doi:10.7203/SCRIPTA.6.7824 
Lluís Roda. La continuïtat «bioliterària» al País Valencià: de Carles Ros a Carles Salvador (o de Gregori Maians a Vicent Andrés Estellés, passant per Teodor Llorente)

\section{De Constantí Llombart (1848-1893) a Carles Salvador (1893-1955)}

Convé recordar que Teodor Llorente (1836-1911) va voler dedicar Llibret de versos (1885) a Marià Aguiló (1825-1897). I que Constantí Llombart (1848-1893) va voler dedicar Los fills de la morta viva (1883) a Víctor Balaguer (1824-1901). Ens preguntem, ara i ací, qui podia haver estat l'autor d'aquell transcendental «Himne a la llibertat» que tant decisivament va impressionar Vicent Boix (1813-1880). Era una traducció d'algun poeta romàntic com Schiller? Era la composició en català d'un poeta romàntic nostrat? Crec que no se sap, de moment. Ho explica Constantí Llombart (1883: 302 «Vicent Boix»):

\footnotetext{
Allá per los anys de 1835 ó 36, la lectura d’un «Himne á la llibertat,» llavors molt en boga, fon tal l'influéncia qu'en la seua imaginació eixercí, que féntseli per punts estretes les parets del convent, resolgué en 1837 abandonarles, com ho feu, y mamprengué demprés sos viajes per Europa, ab lo cárrech de Secretari del Sr. Marqués de Bellisca.
}

Carles Salvador i Gimeno (València 1893 - 1955) va nàixer el 20 de gener. Constantí Llombart moria un parell de mesos més tard, el 30 de març. L'any 1893 naix també Bernat Ortín i Benedito (València 1893 - 1940). Ja hem subratllat que sorprenentment són molt pocs els autors anteriors a Constantí Llombart vius l'any 1909, l'any emblemàtic de l'Exposició Regional i del multitudinari homenatge a Teodor Llorente, corona inclosa. Carles Salvador tenia sols setze anys l'any 1909. Els mateixos anys que Carmel Navarro jo no era entre els valencians. Tanmateix, l'arbre havia arrelat i anava a mostrar nombrosos brots. Són, sobretot, els nascuts entre 1848 i 1893, els que van protagonitzar els fets i les esperances de 1909: els quaranta-cinc anys que els separen representen més d'una generació, foren suficients per confirmar i per renovar, suficients per no conformar-se. La pèrdua d'un dels referents bàsics, com era Constantí Llombart, durant setze anys crucials, si més no, creava un buit que la relació creixent amb Catalunya i els canvis que allà s'hi produien podien si bé no omplir-lo, sí motivar i esperonar. Començava una esperança més enllà de la literatura. I, per tant, la creació d'un nou espai per a la literatura. Nou. Diferent. Volgudament normal. I aquell trànsit el representa bé la xifra d'autors, quantitativament important, nascuts en vida de Constantí Llombart: la faena multiplicativa era ja feta i tindria un símbol l'any 1909 en la persona de Teodor Llorente. Com hem intentat fer entendre, homenatjant-lo, el poble valencià es reconeixia amb potències i problemes abans desconeguts, inexistents, implantejables. El segle xx tampoc no anava a ser un camí de roses.

La següent és una relació incompleta que sols pretén reconéixer la contribució de tots ells, el seu granet d'arena. Sens dubte, no totes les contribucions van ser igual de decisives, però sí de simptomàtiques, alguna cosa diferent començava a ser possible i anava a suscitar com més va més contradiccions. $\mathrm{O}$ menys. Més ànsia de llibertat. Més autoreconeixement com a poble. Més consciència i més reflexió. Més literatura. I més acció política. 
Lluís Roda. La continuïtat «bioliterària» al País Valencià: de Carles Ros a Carles Salvador (o de Gregori Maians a Vicent Andrés Estellés, passant per Teodor Llorente)

Esmentem els escriptors per ordre cronològic, sense detalls addicionals: Jacob Sales i Reig (València 1849 - Madrid 1905), Joan Baptista Pastor i Aicart (Beneixama 1849 - 1917), Joaquim Maria Bartrina i d’Aixemús (Reus 1850 - Barcelona 1880), ${ }^{42}$ Faustí Barberà (Alaquàs 1850 - València 1924), Víctor Iranzo i Simon (Fortanete, Aragó 1850 - València 1890), Manuel Torres i Orive (València 1851 - 1925), Lluís Cebrian i Mezquita (València 1851 - 1934), Joan Colom i Sales (València 1852 - 1917), Vicent Eugeni Miquel i Madaleno (Altea 1852 - Alacant 1911), Joan Rodríguez i Guzman (València 1852 - 1921), Joan Espiau i Bellveser (València 1853 - 1904), Benet Josep Nebot i Pérez (Vila-real 1853 - València 1914), Eduard Escalante i Feo (València 1854 - València 1921), Lluís Tramoyeres i Blasco (València 1854 - 1920), Josep Maria Puig i Torralva (València 1854 - 1911), Ricard Cester i Llorente (València 1855 - València d. 1885), Manuel Peris i Fuentes (Borriana 1857 - 1932), Francesc Badenes i Dalmau (Alberic 1858 - 1917), Francesc Vives i Liern (València 1859 - 1915), Estanislau Alberola i Serra (Quatretonda 1861 - 1933), Francesc Martí i Grajales (València 1862 - 1920), Magdalena Garcia i Bravo (València 1862 - 1891), Francesc Barber i Bas (València 1864 - 1897), Josep Maria de la Torre (València 1864 - 1906), Pere Bonet i Alcantarilla (1864-193?), Bernat Morales i Sanmartín (el Cabanyal, València 1864 - València 1947), Pasqual Cucarella i Candel (Xàtiva 1865 - 1917?), Francesc Martínez i Martínez (Altea 1865 - 1946), Julià Sanjuan i Pascual (Morella 1865 - 1949), Josep Borràs i Marco (Alacant, ? - ? s. xx), Salvador Guinot i Vilar (Castelló de la Plana 1866 - 1944), Joaquim Garcia i Girona (Benassal 1866 - Baeza, Andalusia 1928), Lluís de Val (València 1867 - 1930), Josep Sanchis i Sivera (València 1867 - 1937), Vicent Blasco i Ibáñez (València 1867 - Menton, Provença 1928), Jaume Sardà i Ferran (Reus 1868 València 1939), Enric Ribés i Sangüesa (Castelló 1868 - 1936), Josep Ėpila i Simón (València 1868 - 1923), Teodor Llorente i Falcó (València 1869 - 1949), Joaquim Montero i Delgado (València 1869 - Santiago de Xile 1942), Vicent Calvo i Acacio (València 1869 - 1953), Ramon Andrés i Cabrelles (Campanar, València 1869 - 1957), Lluís Bernat i Ferrer (València 1870 - 1920), Leopold Trenor i Palavicino (Madrid 1870 - València 1937), Eduard López-Chávarri i Marco (València 1871 - València 1970), Lluís Fullana i Mira (Benimarfull 1871 - Madrid 1948), Josep Ribelles i Comín (Castelló 1872 - Barcelona 1951), Pere Martí i Peydró (Alcoi 1872 - Sabadell 1956), Joaquim Amo (Monòver 1873 - 1914), Víctor Navarro i Reig (a. 1875 - d. 1916), Vicent Fe i Castell (València 1875 - València ?), Maximilià Thous i Orts (San Esteban de Pravia, Astúries 1875 - València 1947), Josep Navarro i Cabanes (Ontinyent 1875 - València 1929), Nicolau-Primitiu Gómez i Serrano (Sueca 1877 València 1971), Manuel González i Martí (València 1877 - 1972), Severí Guastavino i Robba (València 1879 - 1950), Santiago Cebrian i Ibor (València 1880 - 1925), Rodolf Salazar i Navarro (Alacant 1880 - 1937), Rafael Martí i Orberà (València 1881 - Madrid 1963), Josep Ferrandis i Torremocha (Alacant 1882 - 1965), Gaetà Huguet i Segarra (Castelló de la Plana 1882 - 1959), Eduard Genovés i Olmos (Xàbia 1882 - Burjassot 1922), Josep Ernest Peris i Celda (València 1882 - 1960), Salvador Carreres Zacarés (València 1882 - 1973), Josep Carbonell i Botella (Cocentaina 1883 - 1914), Eduard Martínez i Ferrando (València 1883 - 1935), Miquel Duran i Tortajada (València 1883 - 1947), ${ }^{43}$ Josep Pascual

42 Germà de Francesc Bartrina i d’Aixemús (Reus 1846 - Barcelona 1917). Eren fills d'un comerciant valencià.

43 Conegut també com Miquel Duran de València.

SCRIPTA, Revista internacional de literatura i cultura medieval i moderna, núm. 6 / desembre 2015 / pp. 60 - 99 ISSN: 2340-4841 · doi:10.7203/SCRIPTA.6.7824 
Lluís Roda. La continuïtat «bioliterària» al País Valencià: de Carles Ros a Carles Salvador (o de Gregori Maians a Vicent Andrés Estellés, passant per Teodor Llorente)

i Tirado (Castelló 1884 - 1937), Josep Sanç i Moia (Alcoi 1884 - València 1962), Maximilià Alloza (Castelló de la Plana 1885 - 1945), Lluís Cebrian i Ibor (València 1885 - 1941), Andreu Ivars i Cardona (Benissa 1885 - Gata 1936), Josep Monmeneu i Gómez (València 1886 - 1941), Josep Maria Bayarri i Hurtado (València 1886 - València 1970), Jacint-Maria Mustieles i Perales de Verdonces (València 1887 - Barcelona 1948), Daniel Martínez i Ferrando (València 1887 - Ciutat de Mallorca 1953), Marià Ferrandis i Agulló (València 1887 - Xirivella 1924), Lluís Soler i Terol (València 1888 - Manresa 1958), Vicent Clavel i Andrés (València 1888 - Barcelona 1967), Faust Hernández i Casajuana (València 1888 - 1972), Ricard Sanmartín i Bargues (València 1888 - 1974), Josep Maria Esteve i Victòria (la Llosa de Ranes 1889 - València 1936), Francesc Alcayde i Vilar (València 1889 - 1973), Joan Baptista Porcar i Ripollés (Castelló de la Plana 1889 - 1974), Lluís Martí i Alegre (València 1890 - 1972), Anna Rebeca Mezquita (Onda 1890 - San Cristóbal de la Laguna 1970), Rafael Gayano i Lluch (València 1890 - 1954), Vicent Miguel i Carceller (València 1890 1940), Vicent Tomàs i Martí (Artana c. 1890 - 1924), Jesús Ernest Martínez i Ferrando (València 1891 - 1965), Enric Navarro i Borràs (València 1891 - València 1943), Maria Ibars i Ibars (Dénia 1892 - 1965), Francesc Puig i Espert (València 1892 - Asnières-sur-Seine, Illa de França 1967), Lluís Revest i Corzo (València 1892 - Castelló de la Plana 1963). Sense oblidar Pasqual Orozco i Sanz (Alacant, ? - Alacant 1921) ni Rafael Frederic Martínez i Miñana (Belgrad 1959), dels quals ignorem la data de naixença. ${ }^{44}$

En relació a alguns membres d'aquesta gernació d'escriptors nascuts en vida de Constantí Llombart (1848-1893), que hem vist que donà fruits bibliòfils importants, va dir Fuster (1962: 230):

\footnotetext{
En 1906 hi ha alguna cosa que comença a canviar. Són uns petits grups de joves [...] No són ja literats -i n’hi ha que fan versos, és clar!-, sinó polítics: Miquel Duran [1883-1947], Eduard Martínez i Ferrando [1883-1935], Vicent Tomàs i Martí [c. 1890 - 1924] són els tres més destacats. $^{45}$
}

\section{L'homenatge a Teodor Llorente de 1909 i Carles Salvador}

En relació a l'homenatge a Teodor Llorente de 1909, Roca (2004: 65-70) diu: «comptà amb el concurs i la fervent adhesió de la pràctica totalitat de la ciutat i el país». I fa bé de recordar-nos tot seguit:

\footnotetext{
Tanmateix, el que no s'ha destacat tan sovint és que ben pocs personatges de la història del poble valencià han estat capaços de congregar una multitud com la que fou capaç d'agrupar Llorente (es calcula que hi havia al voltant de 140.000 persones)
}

44 Nom de ploma: Federico Miñana. No tenim cap dada de Manuel Robert Mollà (1870-1919), esmentat per Sanchis (1982: 129) dins la Generació de Lo Rat Penat (1878-1907).

45 Els claudàtors són nostres.

SCRIPTA, Revista internacional de literatura i cultura medieval i moderna, núm. 6 / desembre 2015 / pp. 60 - 99 ISSN: 2340-4841 · doi:10.7203/SCRIPTA.6.7824 
Roca hi rememora també el conegut episodi que emmarca, a més d'un relleu generacional, que era evident, també la sòlida connexió històrica que aquells joves anaven a tenir novament la responsabilitat d'actualitzar i fer créixer endavant. Com així fou.

\begin{abstract}
A la nit, finalitzats els actes oficials i de retorn a casa, una trentena de membres de la Joventut Valencianista varen aclamar el poeta als crits de «Visca Llorente!», «Visca València lliure!»i «Visca la llengua valenciana». Eren el grup de joves escriptors [...] Aquell «contrahomenatge» particular no va ser ben vist per tothom, i fou contestat amb crits de «Viva España.» $\mathrm{i}$ «Valencia española.». ${ }^{46}$
\end{abstract}

Arran de la mort de Teodor Llorente, El Mercantil Valenciano afirmava el 3 de juliol de 1911: «con él hemos enterrado la ilusión de un renacimiento de la poesía y de la literatura valenciana» (Roca 2004: 72).

Lluís Guarner (1902-1986) (1983: 70) ho explicava així: «veient que solament els poetes joves estaven al seu costat i entenien el seu llenguatge, encara que ell ja no podia entendre el llenguatge dels nous poetes... Era la transició al modernisme que naixia en els escriptors de la nova generació».

Vegeu-ne el resum de Villafranca (2011: 46-48):

Així, el 14 de novembre del 1909, en l'Exposició Regional Llorente és coronat Poeta de València. Esta fita assenyala el final de la Renaixença i l'inici d'una nova etapa de les lletres valencianes

La coronació de Llorente a València és un fet extraordinari, però que compta amb precedents d'altres llocs, com el del poeta Manuel José Quintana coronat per Isabel II el 1855. El març del 1886, Jacint Verdaguer també va ser coronat com a Poeta de Catalunya, i José Zorrilla rebé la mateixa distinció el 1889 a Granada.

L'homenatge a Llorente el 1909 va ser segurament l'últim que es féu a l'Estat espanyol. La coronació durà uns quants dies. El 14 de novembre va ser la coronació i el dia 15 tingué lloc, en la sala d'actes de l'Exposició, una vetlada literària organitzada en el seu honor per l'Ateneu Científic i Literari i per Lo Rat Penat. La celebració s'allargà, encara, durant els dies 17 i 18 de novembre i el 2 de desembre s'acabà amb l'homenatge de la societat orfeonística El Micalet. $[\ldots]$

Amb el modernisme de la generació del 1909, Jacint Maria Mustieles, Miquel Duran de València, Eduard López Chávarri i Daniel Martínez Ferrando, entre altres, canviaren l'estat de les lletres valencianes i renovaren la mètrica, la prosa i la temàtica. La generació del 1909, a més de ser una generació literària, també ho va ser política: fundà Valencia Nova (1904) i Joventut Valencianista (1908), inicià la publicació de les revistes Lo Crit de la Pàtria (1907) i Renaixement (1908) i promogué el 1907 l'Assemblea Regionalista Valenciana.

Esta generació reivindicà Llorente com a mestre i com a referent, tot i que no coincidien en el plantejament polític ni en les formes poètiques. Però saberen agafar el relleu tal com demostraren en l'homenatge del 1909, on li dedicaren poemes i discursos i li lliuraren una

46 Veg. «De la coronació de Llorente. Missatge al poeta. La veu de la joventut», dins Almanaque Las Provincias per a 1910 , pp. 159-162. També Roca (2007b, 2011) i Villafranca.

SCRIPTA, Revista internacional de literatura i cultura medieval i moderna, núm. 6 / desembre 2015 / pp. 60 - 99 
corona no de llorer sinó de roses. Liquidaren així una etapa de la història de la literatura i del valencianisme del segle XIx. Llorente visqué amb entusiasme l'homenatge dels jóvens valencianistes, que li dedicaren diverses composicions poètiques, entre les quals es troba la de Daniel Martínez Ferrando.

L’emotiu i ben significatiu poema diu així (Roca 2007b: 124-125):

Lo que digueren els jóvens... A D. Teodor Llorente

(Poesia llegida en el Saló d'Actes de la Exposició Nacional de Valencia (1909), en la velada en llahor del gran poeta, ab motiu del seu Homenatge)

D'Amor una ofrena venim a portar-te, ¡oh Mestre!, trovaire cantor del cel clar cantor de les terres pel sol invadides que'l Túria feconda, que besa la mar.

Cantares les glòries més grans d'esta terra, cantares tristeses naixcudes del cor, costums de València que t'ama cantares y ab tu nostra llengua trobà son cantor.

Al vore't en l'alta montanya de glòria que alsat per les muses tocares lo cim, venim a ofrenar-te corona de roses. Nosaltres som jóvens... llorers no tenim.

La teua gran obra trobà son santuari; tu ja l'endivines; està en nostres pits; $i$ al nom de tes obres, com coses sagrades, de cor com pregàries seran els glatits.

En nits que la lluna argente les hortes voràs en les reixes dels nostres jardins les nóvies que callen, sentint ta poesia, com cant que reciten d'amor els fadrins.

Les flors que'n la vida per nom ne tingueren tan sols la paraula del pobre pastor, voràs replegades, els jóvens t’ho diuen, i el llaç que les lligue serà el del amor.

I més que de marbres palaus ab grans torres qu'escolten del aire gemechs i tristors, voldrem la barraca com una gavina, blanqueta i bledana, que amaguen les flors.

Les cartes que escriu lo soldat en la guerra, tan tristes, tan pures, tan santes, tan grans, farem que s'acaben, que acaben les guerres, que mira hon senyalen $a b$ fe nostres mans... 
Lluís Roda. La continuïtat «bioliterària» al País Valencià: de Carles Ros a Carles Salvador (o de Gregori Maians a Vicent Andrés Estellés, passant per Teodor Llorente)

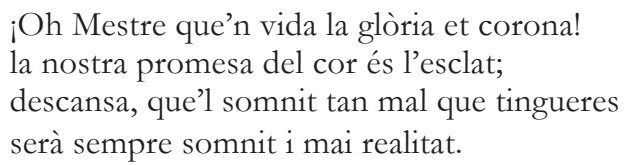

Sens dubte, el poeta Teodor Llorente (València 1836 - 1911), l'amic de Frederic Mistral (Malhana, Provença 1830 - 1914) i de Jacint Verdaguer (Folgueroles 1845 - Vallvidrera 1902), havia esdevingut ja un símbol per als valencians. Es tancava gloriosament, així, la Renaixença valenciana. I els reptes i les esperances lingüístiques, literàries, culturals, polítiques i nacionals esdevenien ja una responsabilitat del segle $\mathrm{xx}$.

L'any 1909, van tenir lloc diferents esdeveniments. Entre els quals, una lectura de Jacint Mustieles de «La veu de la joventut». S'ha conservat una foto molt especial. El peu de la imatge publicada (Barreda 2013b: 225) diu: ${ }^{47}$

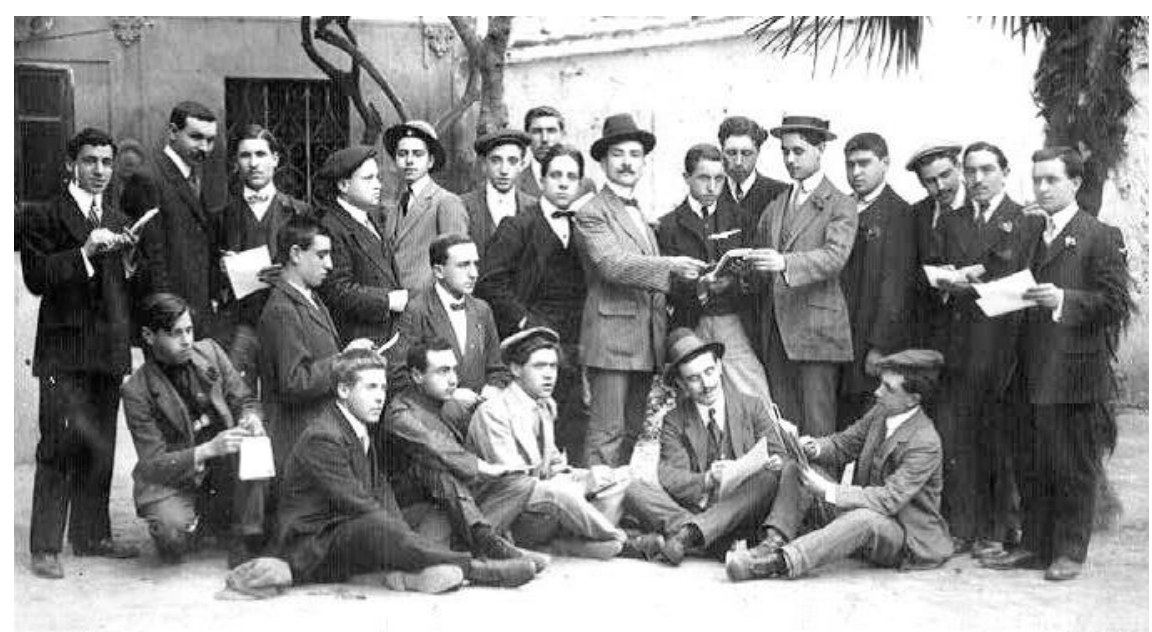

1909: única fotografia conservada de l'acte de lectura de Jacint Mustieles [1887-1948], acompanyat d'una vintena de poetes joves, entre ells Miquel Duran i Tortajada [1883-1947], Daniel Martínez i Ferrando [1887-1953], Bernat Ortín [1893-1940] (el darrer, a la dreta), Josep Maria Bayarri [1886-1870]... i un jove Carles Salvador [1893-1955] de setze anys que posa decididament a la dreta de Mustieles.

El document gràfic és ben il lustratiu. Hi ha un joveníssim Carles Salvador, junt amb Bernat Ortín, tots dos als setze anys. Hi són ja, entre els joves poetes que esdevindran els màxims referents de la generació de 1909. La generació de 1930 hi brollava també, amb un joveníssim Carles Salvador. La continuïtat esdevenia possible. Una connexió directa s'establia amb major o menor grau de consciència amb la realitat literària i social anterior, simbòlicament, però també realment.

47 Els claudàtors són nostres. La fotografia reproduïda és propietat de Carles i Imma Salvador Sales. També apareix publicada a Barreda (2013c: 58).

SCRIPTA, Revista internacional de literatura i cultura medieval i moderna, núm. 6 / desembre 2015 / pp. 60 - 99 
Lluís Roda. La continuïtat «bioliterària» al País Valencià: de Carles Ros a Carles Salvador (o de Gregori Maians a Vicent Andrés Estellés, passant per Teodor Llorente)

Tot fa pensar que Carles Salvador devia ser també entre aquells joves que van aclamar Teodor Llorente pel carrer. I si no, en va viure l'ambient a València, d’on era i residia.

El primer poemari de Carles Salvador, Plàstic, és de 1923 i du un «Portic» de Josep Maria Bayarri: «Amic: Dels armetllers». Però el 1913, el poeta del Poema del viatge a l'entorn de l'amor (1934) i d'El fang i l'esperit (1952) ja havia començat la seua vida d'escriptor i periodista en el setmanari valencianista Foc i Flama (Barreda 2013c: 59), fundat per Josep Maria Esteve i Victòria (1889-1936), en els vinti-cinc números del qual, publicats entre el 14 de desembre de 1912 i el 7 de juny de 1913, trobem col laboracions de Josep Navarro i Cabanes, el Velluter (1875-1929), Josep Maria Bayarri (18861970), Faustí Barberà i Martí (1850-1924) i Jacint Maria Mustieles (1887-1848), entre altres (Givanel 1937, II: 538). Segons Simbor (1993: 7-8):

Coincidint amb la incorporació en l'Escola Normal de València entra en contacte amb el moviment valencianista. Si bé anys abans ja havia assistit als Jocs Florals i se li havia encomanat la inquietud nacionalista, és a partir de la celebració de l'Assemblea Regionalista Valenciana, organitzada l'any 1907 per la societat València Nova, quan Carles Salvador s'incorporà activament a la causa nacionalista.

\section{De Carles Salvador (1893-1955) a Vicent Andrés Estellés (1924-1993)}

Siga com siga, Carles Salvador tampoc no estigué sol a l'hora de dur endavant la responsabilitat heretada. I volem acabar la nostra presentació d'aquest context històric, d'aquest esforç cultural tan lloable com extraordinari, esmentant també alguns d'aquells autors nascuts després de Carles Salvador dels quals hem rebut el testimoni vital, lingüístic i literari del nostre poble.

És a dir: Carles Salvador (València 1893 - 1955), Bernat Ortín i Benedito (València 1893 - 1940), Juli Just i Gimeno (València 1894 - París 1976), Àngel Sànchez i Gozalbo (Castelló 1894 - 1987), Francesc Caballero i Muñoz (València 1894 - 1982), Hermenegild Corbató i Mata (Vila-real 1894 - ?), Salvador Verdeguer i Sapena (València 1894 - 1973), Enric Duran i Tortajada (València 1895 - 1967), Ignasi Villalonga i Villalba (València 1895 - Benicàssim 1973), Pasqual Asins i Lerma (València 1896 - Benimaclet 1948), Eduard Martínez-Sabater i Seguí (Xest 1896 - València 1946), Honori Garcia i Garcia (La Vall d’Uixó 1896 - 1953), Joaquim Reig i Rodríguez (València 1896 Madrid 1989), Emili Gascó i Contell (València 1898 - 1974), Felip Melià i Bernabeu (València 1898 - ?), Eduard Buil i Navarro (València 1898 - 1973), Jesús Morante i Borràs (Quart de Poblet 1899 - València 1971), Llorenç Sorlí i Ballester (Cervera del Maestrat 1899 - Barcelona 1964), Miquel Peña i Masip (Castelló de la Plana 1899 - 1975), Maximilià Thous i Llorenç (València 1900 - 1957), Joan Lacomba i Guillot (el Cabanyal 1900 - 1963), Josep Castanyer i Fons (València 1900 - París 1951), Salvador Roda i Soriano (València 1900 - 1975), Amadeu Pitarch Chiveali (...1914...), Adolf Pizcueta (València 1901 - 1989), Felip Mateu i Llopis (València 1901 - Barcelona 1998), Francesc Bosch i Morata (Xàtiva 1901 - Mexicali, Mèxic 1950), Lluís Guarner i Pérez (València 1902 - 1986), Francesc Martínez i Morellà (València 1902 - Alacant 1947), Casimir Melià i Tena (Albocàsser 
Lluís Roda. La continuïtat «bioliterària» al País Valencià: de Carles Ros a Carles Salvador (o de Gregori Maians a Vicent Andrés Estellés, passant per Teodor Llorente)

1902 - 1991), Emili Beüt i Belenguer (València 1902 - 1993), Artur Perucho i Badia (Borriana 1902 - Mèxic 1956), Emili Cebrian i Navarro (València 1902 - 1982), Josep Bolea i Gorgonio, Josep Alcira (Alzira 1903 - Mèxic DF 1987), Alfred Sendín i Galiana (Xàtiva 1903 - ? 1985), Enric Soler i Godes (Castelló de la Plana 1903 - València 1993), Francesc Almela i Vives (Vinaròs 1903 - València 1967), Bernat Artola i Tomàs (Castelló de la Plana 1904 - Madrid 1958), Prudenci Alcon i Mateu (1904 - 1977), Angelí Castanyer i Fons (Huéneja, Andalusia 1905 - València 1974), Vicent Casp i Verger (Carlet 1906 - Palma 1992), Joan Beneyto i Pérez (La Vila Joiosa 1907 - Madrid 1994), Antoni Igual i Úbeda (València 1907 - Alzira 1983), Emili Gómez i Nadal (València 1907 - València d'Agen, Llenguadoc 1994), Josep Barberà i Ceprià (Benicàssim 1908 - Castelló de la Plana 1977) Lluís Sales i Boli (Castelló de la Plana 1908 - 1981), Jordi Valor i Serra (Alcoi 1908 - 1984), Martí Domínguez i Barberà (Algemesí 1908 - València 1984), Vicent Genovés i Amorós (València 1909 - 1988), Emili Roca i Salvador (1909 - ?), Josep Mascarell i Gosp (Alcalà de Xivert 1910 - València 1977), Enric Valor i Vives (Castalla 1911 - València 2000), Manuel Sanchis Guarner (València 1911 - 1981), Miquel Adlert i Noguerol (Paterna 1911 - 1989), Joan Simon i Matutano (Castelló de la Plana 1911 - 2004), Josep Bea i Izquierdo (1912-1984), Matilde Llòria (Almansa, Castella 1912 - València 2002), Eduard Soler i Estruch (Castelló de la Ribera 1912 - ? 1999), Gonçal Castelló i Gómez-Trevijano (Gandia 1912 - Barcelona 2003), Emili Panach i Ramos (Alboraia 1913 - València 1983), Antoni Santos i Antolí (València 1914 - Barcelona 1987), Empar Beatriu Martínez i Civera (València 1914 - 1995), Xavier Casp (Carlet 1915 - València 2004), Francesc Carreres i de Calatayud (València 1916 - 1989), Josep Lluís León i Roca (València 1916 - 2007), Joan Valls (Alcoi 1917 - 1989), Assumpta González i Cubertorer (Borriana 1917 - Barcelona 2003), Miquel Peris i Segarra (Castelló 1917 1987), Francesc Ferrer i Pastor (la Font d'en Carròs 1918 - València 2000), Vicent Badia i Marín (València 1919 - 1995), Alfred Giner Sorolla (Vinaròs 1919 - 2005), Vicent Ferrís i Garcia (Algemesí 1919 - València 2012), Ricard Blasco i Laguna (València 1921 - Madrid 1994), Joan Fuster (Sueca 1922 - 1992), Jaume Bru i Vidal (Sagunt 1922 - 2000), Alfons Verdeguer i González (València 1923 1971), Vicent Ventura i Beltran (Castelló 1924 - València 1998), Vicent Andrés i Estellés (Burjassot 1924 - València 1993)...

Vicent Andrés Estellés escriu l'article «Carles Salvadon» a Quatre elogis i quatre cues (Salvador 1973). Quinze anys abans, Carles Salvador havia prologat i antologat Teodor Llorente (1958). Anys després, al seu torn, Ricard Blasco (1921-1994) va prologar i antologar Carles Salvador (1981). Posteriorment, Blasco (1988) va enquadrar el treball «Notes per a l'estudi del llenguatge figurat en els poetes valencians (de la Renaixença a la II República)» entre dues citacions de Vicent Andrés Estellés.

Sota la dinàmica complexa dels canvis, les connexions -temporals i espacials- que subjauen a les transmissions culturals i literàries se'ns mostren evidents. Possiblement són la norma en la història de la civilització. I creure el contrari se'ns fa com més va més absurd. En qualsevol cas, cada estat de coses -heretat o provocat-afavoreix o dificulta -en major o menor grau- unes o altres possibilitats de futur. De continuïtat i de canvi. D'adaptació i d'actualització. I, molt desitjablement, de millora. Per a tots. Els valencians no som una excepció. Ni la cultura catalana tampoc.

SCRIPTA, Revista internacional de literatura i cultura medieval i moderna, núm. 6 / desembre 2015 / pp. 60 - 99 ISSN: 2340-4841 · doi:10.7203/SCRIPTA.6.7824 
Lluís Roda. La continuïtat «bioliterària» al País Valencià: de Carles Ros a Carles Salvador (o de Gregori Maians a Vicent Andrés Estellés, passant per Teodor Llorente)

\section{Bibliografia}

Aguiló i Fuster, Marian (1977 [1a. ed. 1923]) Catálogo de obras en lengua catalana impresas desde 1474 basta 1860 (Madrid, Tip. Sucesores de Rivadeneyra), Barcelona, Curial, edició facsímil.

Almela i Vives, Francesc (1949) El editor don Mariano de Cabrerizo, València, CSIC.

—. (1957) El Fénix (Valencia 1844-1849), Madrid, CSIC.

—_. (1962) El Liceo Valenciano, Castelló de la Plana, SCC, 57 p.

Andrés Estellés, Vicent (1973) «Carles Salvador» (dins Salvador 1973).

Aparisi y Guijarro, Antonio (1873) Obras: biografia, pensamientos y poesias, vol. I, Madrid.

Archilés Cardona, Ferran (ed.) (2011) La regió de l'Exposició: la societat valenciana de 1909, València, PUV.

Ardit Lucas, Manuel (2011) «Horneros, negociantes y corsarios. Los orígenes de la fortuna de Vicente Bertrán de Lis y Tomás», Estudis: revista de historia moderna, 37, Universitat de València, pp. 155-178.

Astorgano Abajo, Antonio (2005) «El inquisidor Rodríguez Laso y el ocaso de la Inquisición valenciana (1814-1820)», Cuadernos de Ilustración y Romanticismo, 13, Cádiz, Publicaciones de la Universidad, pp. 297-345.

Balaguer, Enric (1988) «Literatura a les comarques del Sud», L'Aiguadolç (Dossier: La Renaixença), 6, Dénia, pp. 9-34.

—. (1994) «Avanguarda, populisme i literatura kitsch: la generació de 1930 i el redreçament literari» (dins Pérez / Simbor 1994).

Barreda, Pere Enric (2013a) «Escriure per al calaix: nova datació d'obres de Carles Salvador», III Congrés de Cultura i Territori a les comarques de la diòcesi de Tortosa (Vinaròs, 2011), Benicarló, Onada, pp. 83-93.

—. (2013b) Carles Salvador, mestre de Benassal (1916-1934): I Antologia de textos, Benassal, Fundació Carles Salvador/Institut d'Estudis Catalans.

. (2013c) «Noves dades sobre la biografia i obra de Carles Salvador», Anuari de Filologia. Literatures Contemporànies, 3/2013, ISSN 2014-1416, p. 58.

Bas Martín, Nicolás (2002) Las bibliografías de la Ilustración valenciana, València, Institució Alfons el Magnànim.

(2006) «Apertura política e intelectual de los impresores valencianos de la Ilustración al Liberalismo», dins Canterla, C. (ed.) Nación y Constitución. De la Ilustración al Liberalismo, Consejería de Innovación, Ciencia y Empresa de la Junta de Andalucía/Universidad Pablo de Olavide/ Sociedad Española de Estudios del Siglo XviII, pp. 83-104.

SCRIPTA, Revista internacional de literatura i cultura medieval i moderna, núm. 6 / desembre 2015 / pp. 60 - 99 ISSN: 2340-4841 · doi:10.7203/SCRIPTA.6.7824 
Lluís Roda. La continuïtat «bioliterària» al País Valencià: de Carles Ros a Carles Salvador (o de Gregori Maians a Vicent Andrés Estellés, passant per Teodor Llorente)

—_. (2013) «Un soplo de aire fresco: libros franceses en los Catálogos del siglo XVIII de la librería Mallén de Valencia», Revista General de Información y Documentación, vol. XXIII, pp. 173-201.

Blasco, Ricard (1981) «Una lectura de Carles Salvador» (dins Salvador 1981).

—_. (1987) «Pròleg» (dins Martí Grajales 1987).

—_. (1988) «Notes per a l'estudi del llenguatge figurat en els poetes valencians de la Renaixença a la II República», L'Aiguadolç (Dossier: La Renaixença), 6, Dénia, pp. 41-74.

—_. (1993) «Carles Salvador i Gimeno (1893-1955)», Revista de Catalunya, 80.

Boix, Vicent (ed.) (1855) Fiestas que en el siglo IV de la canonización de San Vicente Ferrer se celebraron en Valencia, València, Societat Econòmica d'Amics del País, Impremta de José Rius

Bou, Enric (dir.) (2000) Nou diccionari 62 de la literatura catalana, Barcelona, Ed. 62.

Broch, Àlex (dir.) (2008) Diccionari de la literatura catalana, Barcelona, Enciclopèdia Catalana.

Carbó, Ferran (1994) «Carles Salvador en la cruilla de la recuperació poètica valenciana» (dins Pérez / Simbor 1994).

Casanova, Emili (1987-1989) «Valencià versus castellà als segles XVIII i XIx i Vicent Salvà», dins Estudios Románicos, vol. IV, Universidad de Murcia, pp. 197-217.

Climent Martínez, Josep Daniel (2003) L'interés per la llengua dels valencians (segles XV-XIX), València, Consell Valencià de Cultura.

Cortés, Santi (1991) «Premsa literària valenciana de postguerra: el cas de l'Almanaque de Las Provincias (1940-1951)», dins Carbó, F. (ed.) Literatura de postguerra al País Valencià, Caplletra, 10, IUFV.

Cucó, Alfons (1973) «Epíleg» (dins Salvador 1973).

Diversos autors (1855) Album poético a la terminación del ferro-carril del Grao de Valencia a Játiva, dedicado al Señor Don José Campo, València, Impremta de José Rius.

Escartí, Vicent Josep (2012) From Renaissance to Renaissance. (Re)creating Valencian Culture (15th. - 19th. c.), Santa Bárbara/Mèxic, eHumanista/Oro de la Noche.

Fabregat, Amadeu (1974) Carn fresca: poesia valenciana jove, València, L'Estel.

Faubell Zapata, Vicente (1983) Diccionario Enciclopédico Escolapio (DENES): Biografías de escolapios, vol. II, Instituto Calasanz de Ciencias de la Educación/Ediciones Calasancias.

Faubell Zapata, Vicente (1990) Diccionario Enciclopédico Escolapio (DENES): Presencia de Escuelas Pías, vol. I, Instituto Calasanz de Ciencias de la Educación/Ediciones Calasancias.

Ferrando, Antoni (1983) Els certàmens poètics valencians del segle XIV al XIX, València, Institució Alfons el Magnànim.

Fuertes Zapata, Joan Vicent (2014) «La font de Llíria: Edició del primer milacre vicentí publicat (1822)», SCRIPTA: Revista internacional de literatura $i$ cultura medieval $i$ moderna, 4, pp. 96-110. 
Lluís Roda. La continuïtat «bioliterària» al País Valencià: de Carles Ros a Carles Salvador (o de Gregori Maians a Vicent Andrés Estellés, passant per Teodor Llorente)

Fuster i Ortells, Joan (1956) Antologia de la poesia valenciana (1900-1950), Barcelona, Selecta. (2a. ed. 1980) València, Eliseu Climent.

—. (1962) Nosaltres els valencians, Barcelona, Ed. 62, 3a. ed. 1977.

—. (1976) La decadència al País Valencià, Barcelona, Curial.

Fuster i Taronger, Just Pastor (1827-1830) Biblioteca valenciana de les escritores que florecieron hasta nuestros días, València, Josep Ximeno/Ildefons Mompié, 2 vol. (1980) València, Llibreries París-València, facsímil.

Galindo y de Vera, León (1873) «Biografía» (dins Aparisi: 1-157).

Garcia i Frasquet, Gabriel (2000) «Rafael Vives Azpiroz, un dramaturg valencià de biografia atípica i d'obra tòpica», dins Estudis de Llengua i Literatura Catalanes/XL: Homenatge a Arthur Terry 4, Associació Internacional de Llengua i Literatura Catalanes/PAM, pp. 57-70.

Genovés i Olmos, Eduard (1911-1914) Catalech descriptiu de les obres impreses en llengua valenciana, València, Imp. Manuel Pau, 4 vol.: [1] 1474-1700 [2] 1701-1880 [3] 1881-1910 [4] Addenda i taules.

Giné, Marta (1999) «Traducciones, en España, de Atala y René de Chateaubriand» (dins Lafarga 1999: 353-362).

Givanel i Mas, Joan (1931-1937) Bibliografia catalana: premsa, Barcelona, Institució Patxot/IEC, 3 vol.

Guarner, Lluís (1980) «Pròleg», dins Guarner, Lluís (ed.) V. W. Querol: Rimes Catalanes, València, Tres i Quatre.

—_. (1983) «Pròleg», dins Teodor Llorente. Poesia valenciana completa, València, Tres i Quatre, pp. 1990.

Hernández, Telesforo M. (1997) «Enseñanza de latinidad y humanidades en la renovación pedagógica del seminario andresiano de nobles (1763-1785)», Estudis: revista de historia moderna, 23, pp. 269-296.

. / León Navarro, Vicente (2002) «El Real Seminario de Nobles Educandos de Valencia (17671784). ¿Un símbolo del reformismo educativo?», Anales valentinos: revista de filosofía y teología, pp. 129-154.

Lafarga, Francisco (ed.) (1999) La traducción en España (1750-1830). Lengua, literatura, cultura, Universitat de Lleida.

(2013) «De Gresset a Martínez Colomer o un (serio) franciscano traduciendo una obra festiva», dins Martino Alba, P. et al (ed.) Al bumanista, traductory maestro Miguel Ángel Vega Cernuda, pp. 135-144.

La Parra López, Emilio (1985) El primer liberalismo español y la Iglesia. Las Cortes de Cádir, Alacant, Institut de Cultura Joan Gil-Albert. 
Lluís Roda. La continuïtat «bioliterària» al País Valencià: de Carles Ros a Carles Salvador (o de Gregori Maians a Vicent Andrés Estellés, passant per Teodor Llorente)

La Parra, E. / Ramírez, G. (eds.) (2003) Elprimer liberalismo: España y Europa, una perspectiva comparada, València, Biblioteca Valenciana.

León Navarro, Vicente (1998) «Juan Bautista Hermán: discípulo de Gregorio Mayans. Los entresijos de la curia valenciana. Una persecución en dos actos», dins Saitabi, 48, pp. 51-78.

Llombart, Constantí (1883) Los fills de la morta-viva: apunts bio-bibliogräfichs pera la bistòria del Renaiximent lliterari llemosi en València, València, Impremta d’Emili Pasqual. (2005) AVL, facsímil.

Llorens Casteillo, Vicente (1968) Liberales y románticos. Una emigración española en Inglaterra (18231834), Madrid, Castalia.

Llorente, Teodor (1958) Antologia poètica, Carles Salvador (antol.), València, Sicània.

López Pampló, Gonçal (2011) «Introducció» (dins Salvador 2011).

- (2012) «La conferència “Llorente i els infants” de Carles Salvador (1948). Estudi i transcripció» (dins Roca 2012a).

Martí i Badia, Adrià (2014) «La contribució de Vicent Boix i Ricarte (1813-1880) a la recuperació de la consciència lingüística dels valencians», eHumanista/IVITR A, 5, pp. 52-74.

Martí Grajales, Francesc (1927) Ensayo de un diccionario biográfico y bibliográfico de los poetas que florecieron en el Reino de Valencia basta el año 1700, Madrid, Tip. de la Revista de Archivos, Bibliotecas y Museos.

—_. (1987) Ensayo de una bibliografia valenciana del siglo XVIII, Diputació de València.

Meseguer, Lluís (1994) «La poètica de Carles Salvador i la generació de 1930» (dins Pérez / Simbor 1994).

Nicolàs, Miquel (ed.) (2002) Bernat i Baldoví i el seu temps, Universitat de València.

Pérez Saldanya, Manuel / Simbor, Vicent (eds.) (1994) Caplletra, 16, monogràfic sobre Carles Salvador, Barcelona/València, PAM/IIFV, imprés 1997.

Pons Pons, Anaclet / Serna Alonso, Justo (2009) «Trenor. Fets i paraules», dins Pons Pons, Anaclet / Serna Alonso, Justo (eds.) Trenor. L'Exposició d'una gran familia burgesa, Universitat de València, pp. 17-104.

Puig Torralva, Joseph M. / Martí Grajales, Francesch (1883) Estudio historico-crítico de los poetas valencianos de los siglos ХИ, ХИІІ Y ХИIII, València, Imp. de la Viuda de Ayoldi.

Ramírez Aledon, Germán (ed.) (1996) Vida literaria de Don Joaquín Lorenzo Villanueva, Alacant, Institut de Cultura Joan Gil-Albert.

—_. (2003) «La Santa Sede ante la revolución liberal española: diplomacia y política en el Trienio Constitucional» (dins La Parra et al 2003).

. Germán (ed.) (2009) Valencianos en Cádiz: Joaquín Lorenzo Villanueva y el grupo valenciano en las Cortes de Cádir, Cádiz, Fundación Municipal de Cultura. 
Lluís Roda. La continuïtat «bioliterària» al País Valencià: de Carles Ros a Carles Salvador (o de Gregori Maians a Vicent Andrés Estellés, passant per Teodor Llorente)

Reig Salvá, Carola (1972) Vicente Salvá, un valenciano de prestigio internacional, València, Institució Alfons el Magnànim.

Ribelles Comín, Josep (1915-1920) Bibliografia de la lengua valenciana: o sea catálogo razonado por orden alfabético de autores de los libros, folletos... etc., que escritos en lengua valenciana y bilingüe, ban visto la luz. pública desde el establecimiento de la imprenta en España hasta nuestros días, València, Imp. de la Rev. de Archivos, Bibliotecas y Museos, 2 vol. (1977) Reed. facsímil.

Roca, Rafael (1997) «Víctor Balaguer i la revista valenciana "El Fénix” (1844-1849)», dins Jorba, M. et al. (eds.) El Segle Romàntic. Actes del Col toqui sobre el Romanticisme, Ajuntament de Vilanova i la Geltrú, pp. 521-528.

—. (2004) Teodor Llorente, el darrer patriarca, Alzira, IIFV/Bromera.

—. (2007a) Teodor Llorente, líder de la Renaixença valenciana, València, PUV.

—. (2007b) Teodor Llorente, i la Renaixença valenciana, València, Institució Alfons el Magnànim.

—. (2011) «La Renaixença valenciana i l’Exposició regional» dins Archilés, F. (ed.) La regió de l'Exposició: la societat valenciana de 1909, Universitat de València.

—. (ed.) (2012a) Teodor Llorente, cent anys després, Alacant, IIFV/UA.

—_. (2012b) «La posteritat de Teodor Llorente» (dins Roca 2012a: 73-89).

—. (2013a) Teodor Llorente: obra valenciana completa, València, AVL.

—_. (2013b) «L'interés de la Renaixença valenciana pels poetes de l'Edat Moderna», eHumanistal IVTTRA, 3, pp. 288-304.

Roda, Lluís (2011a) «Teodor Llorente entre la Renaixença i l’Avenç», Caràcters, 57, València, pp. 34-35.

_. (2011b) «"Llibre de la Pàtria” (1882), "Llibre de l’Amor” (1882) i “Llibre de la Fe” (1883)», dins Roca, R. (ed.) Teodor Llorente: patriarca de la Renaixença, València, AVL.

_. (2011c) «"Jochs Florals de Lo Rat-Penat de 1907”», dins Roca, R. (ed.) Teodor Llorente: patriarca de la Renaixença, València, AVL.

Rodrigo Mancho, Ricardo (1993) «Vicent Boix i Víctor Balaguer: dues biografies en convergència», dins Ferrando, A. / Hauf, A. (eds.) Miscel lània Joan Fuster, vol. VII, Barcelona, PAM, pp. 199-222.

Rodríguez, José / Savalls, Ignacio (1747) Biblioteca valentina, Valencia, Joseph Tomàs Lucas. ${ }^{48}$

48 Compuesta por Josef Rodriguez, por su muerte interrumpida su impression; aora continuada y aumentada con el prologo y originales del mismo autor; añadidas algunas enmiendas y correcciones como las dexò el autor entre sus originales con que se mejoran muchos lugares de su obra; juntase la continuacion de la misma obra, hecha por Ignacio Savalls (a la p. 460: «Noticia de los escritores valencianos anonimos»; la cont. de l'obra per Savalls comença a la p. 477; a la p. 542: «Indice de aquellos escritores que no siendo valencianos, escrivieron algo de nuestra ciudad ò de nuestro reyno, ò sacaron a luz, ò exornaron, ò impugnaron ò traduxeron diferentes obras de autores naturales de nuestra provincia»). Referències: CCPB 000069181-X, NR 0358817, Palau 272941; 752: dValència.

SCRIPTA, Revista internacional de literatura i cultura medieval i moderna, núm. 6 / desembre 2015 / pp. 60 - 99 ISSN: 2340-4841 · doi:10.7203/SCRIPTA.6.7824 
Lluís Roda. La continuïtat «bioliterària» al País Valencià: de Carles Ros a Carles Salvador (o de Gregori Maians a Vicent Andrés Estellés, passant per Teodor Llorente)

—. (1980 [1a ed. 1747]) Biblioteca valentina, València, Llibreries París-València (Biblioteca valenciana).

Rubió i Ors, Joaquim (1858) Lo Gayter del Llobregat. Poesias (Segona edició. Corretgida y considerablement aumentada), Barcelona, Libreria de Joseph Rubió.

Salvà, Vicent (1940) «Una hoja de álbum... de 1831», dins Almanaque Las Provincias 1940, València, pp. 311-315.

Salvà i Mallén, Pere (1872) Catálogo de la Biblioteca de Salvá escrito por Pedro Salva y Mallen; y enriquecido con la descripción de otras muchas obras, de sus ediciones, etc, València, Ferrer de Orga.

Salvador, Carles (1973) Quatre elogis i quatre cues, València, Ed. Gorg.

—. (1981) Poesia, Ricard Blasco (antol.), València, Institució Alfons el Magnànim.

—_. (1993) Antologia poètica, Vicent Simbor (antol.), València, Consell Valencià de Cultura.

—. (2011) Elogi de la terra i altres poemes, Gonçal López-Pampló (antol.), Alzira, Bromera.

Salvador, Sofia (1994) «Carles Salvador i Gimeno: l'home i l'obra» (dins Pérez / Simbor 1994).

Salvador, Vicent (2001) «La recepció del romanticisme a València: Cabrerizo, Boix, Bonilla», dins Els arxius del discurs: episodis valencians d'història social de la llengua i la literatura, IIFV / PAM, pp. 103122.

Sanchis Guarner, Manuel (1978) El sector progressista de la Renaixença valenciana, Departament de Lingüística Valenciana-Universitat de València.

—. (1982 [1a. ed. 1968]) Renaixença al País Valencià: estudi per generacions, València, Ed. Eliseu Climent.

Sansano, Gabriel (1996) «Mariano de Cabrerizo, llibreter i mercader de llibres», dins M. de Cabrerizo: memorias de mis vicisitudes politicas, Alacant, pp. 7-21.

Sansano, Gabriel / Roca, Rafael (2005) «Vint anys d'estudis i edicions sobre la Renaixença al País Valencià (1984-2004)», Anuari Verdaguer, 13, Societat Verdaguer-Eumo-UVIC, pp. 219-248.

Seguí i Francès, Romà (1999) «Vicent i Pere Salvà o la memòria de la Biblioteca del XIX», Métodos de Información, vol. VI, 31, pp. 25-30.

—. (2005) «La recuperació del patrimoni bibliogràfic valencià al segle XvIII. La Biblioteca Valentina de Josep Rodríguez i Escritores del Reyno de Valencia de Vicent Ximeno», Afers, 52, pp. 703-726.

Simbor, Vicent (1980) Els orígens de la Renaixença valenciana, Universitat de València.

—. (1983) Carles Salvador i Gimeno: una obra decisiva, Diputació de València.

- _. (1987) «El primer romanticisme valencià i l'origen de la Renaixença» dins Alemany, R. (ed.) Estudis de literatura catalana al País Valencià, Universitat d'Alacant, pp. 75-97.

—_. (1988a) «La Renaixença al País Valencià», Caplletra, 4, IFV/PAM, pp. 9-41.

SCRIPTA, Revista internacional de literatura i cultura medieval i moderna, núm. 6 / desembre 2015 / pp. 60 - 99 ISSN: 2340-4841 · doi:10.7203/SCRIPTA.6.7824 
Lluís Roda. La continuïtat «bioliterària» al País Valencià: de Carles Ros a Carles Salvador (o de Gregori Maians a Vicent Andrés Estellés, passant per Teodor Llorente)

. (1988b) Els fonaments de la literatura contemporània al País Valencià (1900-1939), Biblioteca Sanchis Guarner-IFV.

_. (1992) «Un avantguardisme poètic valencià?», dins Ferrando, A. (ed.) Miscel lània Sanchis Guarner, vol. III, Barcelona, PAM.

_. (1993) «Introducció» (dins Salvador 1993).

—_. (1994) «Carles Salvador i la modernització literària valenciana» (dins Pérez / Simbor 1994).

—. (2008) Carles Salvador (1893-1955), Barcelona, Fundació Josep Irla.

Soler Pascual, Emilio (2000) «Los Villanueva: una família aragonesa en el Antiguo Régimen», dins Ferrer Benimeli, J. A. et al (eds.) El conde de Aranda y su tiempo, CSIC/Institución Fernando el Católico.

Tomàs, Margalida (2012) «Les relacions de Teodor Llorente amb Catalunya i Mallorca» (dins Roca 2012a: 31-71).

Tomsich, Maria Giovanna (1972) Eljansenisme en España. Estudio sobre ideas religiosas en la segunda mitad del siglo XVIII, Madrid, Siglo XXI.

Villacañas Berlanga, José Luis (2003) «Las raíces ilustradas del Liberalismo» (dins La Parra et al 2003).

Villafranca Giner, Encarna (2011) Teodor Llorente, patriarca de la Renaixença, Col lecció Didàctica 8, AVL.

Ximeno, Vicente (1747) Escritores del reyno de Valencia: Chronologicamente ordenados desde el año MCCXXXVIII ... hasta el de MDCCXLVII, València, En la Oficina de Josef Estevan Dolz, 2 vol. 